\title{
Roles of Dynamic Forcings and Diabatic Heating in Summer Extreme Precipitation in East China and the Southeastern United States
}

\author{
Ji NIE AND BOWEN FAN \\ Department of Atmospheric and Oceanic Sciences, School of Physics, Peking University, Beijing, China
}

(Manuscript received 7 March 2019, in final form 7 June 2019)

\begin{abstract}
Extratropical regional-scale extreme precipitation events (EPEs) are usually associated with certain synoptic perturbations superimposed on slow-varying background circulations. These perturbations induce a dynamically forced ascent that destabilizes the atmospheric stratification and stimulates deep convection, which further drives the perturbation by releasing latent heat. This study identifies the characteristics of largescale perturbations associated with summer EPEs in two representative regions, East China (ECN) and the southeastern United States (SUS), and analyzes the roles of dynamic forcings and diabatic heating using the quasigeostrophic omega equation. Composites of 39 events in each region show that the upper-level absolute vorticity advection and tropospheric warm advection promote dynamically forced ascent in EPEs, and the moisture advection premoistens the local environment. The background circulation and synoptic perturbations in ECN and the SUS have significant differences. The background vorticity, temperature, and moisture advection form the quasi-steady mei-yu front in ECN, which provides favorable conditions for heavy rainfall. In the SUS, weaker background ascents are forced mainly through vorticity advection. In the synoptic scale, the EPEs in ECN are triggered by short-wavelength wave trains, and in the SUS the EPEs are triggered by longer wavelength potential vorticity intrusions. Although the amplitudes of the dynamically forced ascent in the two regions are similar, diabatic heating contributes much more to the vertical motion in ECN than the SUS, which indicates that there is stronger diabatic heating feedback there. The stronger diabatic heating feedback in ECN appears to be due to stronger moisture advection, convective environments with more humidity, and stronger coupling between convection and large-scale dynamics.
\end{abstract}

\section{Introduction}

Extreme precipitation events (EPEs) have great socioeconomic impacts, since they often lead to natural disasters such as floods, landslides, and urban waterlogging. However, the mechanism of EPEs is still poorly understood. Current global climate models (GCMs) face serious challenges in the simulation of precipitation extremes. For instance, many GCMs underestimate the climatology and interannual variations of precipitation extremes (e.g., Kharin et al. 2007; Shiu et al. 2012), and GCMs show a large intermodel spread of the future projection of precipitation extremes under global warming (O'Gorman and Schneider 2009). Examining the statistical characteristics of EPEs from observations is a useful starting point for developing a deeper understanding of EPEs. The observational characteristics of EPEs and their associated atmospheric circulation

\footnotetext{
Corresponding author: Ji Nie, jinie@pku.edu.cn
}

anomalies also could serve as benchmarks for improving GCM simulations and reducing their uncertainties.

There is an extensive literature on the atmospheric circulation anomalies associated with EPEs of different regions, and these studies showed that EPEs associated with circulation anomalies have significant regional features. For example, the heavy rainfall leading to the devastating 2010 Pakistan flood was associated with a persistent upstream European block and monsoon depressions approaching from the tropics (Houze et al. 2011; Lau and Kim 2012; Martius et al. 2013). Heavy rainfall in central Europe is usually related to wave breaking of a coherent wave packet propagating from the central and eastern Pacific (Martius et al. 2008; Wirth and Eichhorn 2014). While a global survey is out the scope of this study, we focus on summer EPEs of two representative regions, East China (ECN) and the southeastern United States (SUS). One main regional feature of the summer EPEs of ECN is that they are usually embedded in the quasi-steady mei-yu front (e.g., 
Ding and Chan 2005; Luo et al. 2013; Oh et al. 2018). The main factors affecting the EPEs of ECN include upstream blocking highs (Wang et al. 2000; Chen and Zhai 2014), the western Pacific subtropical high (Ding and Chan 2005), the South Asia high (Wang et al. 2000), the westerly jet (Chiang et al. 2017), and the moisture transport by low-level southwesterlies (Zhou and Yu 2005), and their combined effects though potential vorticity (PV) dynamics (Horinouchi 2014; Horinouchi and Hayashi 2017). For the SUS region, free tropospheric troughs (Maddox et al. 1979, 1980), surface frontal systems (Funk 1991), and low-level moisture and warm advection (Konrad and Meentemeyer 1994; Konrad 1997) are usually seen in EPEs. Many of the above studies are based on a single case and thus are unable to determine common features of EPEs. Moreover, since precipitation is directly related with vertical motion rather than horizontal winds, there is still a missing link when relating the circulation anomalies to the EPEs.

Quasigeostrophic omega (QG $\omega$ ) analyses can serve as a useful tool to bridge the gap between large-scale circulation anomalies and local EPEs. The QG $\omega$ equation has been used in the study of weather systems, such as extratropical storms (e.g., Clough et al. 1996; Lareau and Horel 2012), mei-yu fronts (Sampe and Xie 2010; Gu et al. 2018), and EPEs (Martius et al. 2008), to quantify and separate vertical motion caused by perturbations at different levels or regions, taking the advantage of its linearity. However, most previous studies of QG $\omega$ analyses only focus on the dynamically forced vertical motion, those associated with the adiabatically balanced flow. In the EPEs, there is a large amount of diabatic heating due to the water vapor condensation, and the diabatic heating also induces significant large-scale vertical motion (Horinouchi and Hayashi 2017). Recent studies estimated that more than half of the large-scale vertical motion in EPEs is caused by diabatic heating (Nie et al. 2016; Shaevitz 2016).

This study analyses the role of dynamic forcings and diabatic heating in extratropical EPEs, and investigates their interactions. Large-scale adiabatic perturbations induce dynamically forced vertical motion and stimulate the development of deep convection by destabilizing the atmospheric stratification. The latent heat released by convection in turn drives further large-scale ascent by allowing air parcels to rise across surfaces of potential temperature. An extratropical EPE is essentially a largescale-convection coupled system, in which the large-scale perturbations serve as forcings and the convective responses act as a feedback (Nie and Sobel 2016; Nie et al. 2018). We may call this view on EPEs the "dynamic forcing-diabatic feedback" perspective.
The goal of this paper is to identify the characteristics of large-scale conditions, including both the background circulations and the synoptic-scale perturbations, as well as the diabatic heating feedback associated with EPEs. We focus on the summer season EPEs in ECN and the SUS for a comparative study to identify their regional features. These two regions are local maximums of precipitation extremes (e.g., van der Wiel et al. 2016; Sun and Zhang 2017), and their latitudes and Coriolis parameters are similar. The geographic locations of these two regions also share some similarity; they are both roughly located in the southeastern corner of their respective continents and the entrance of the Northern Hemispheric storm tracks. Section 2 introduces the data and methods. Section 3 examines the time evolution of the large-scale advective forcings associated with EPEs, followed by analyses of the horizontal meteorological fields in section 4. In section 5, we examine the dynamically forced and diabatic heating forced vertical motion components and investigate the causes for differences in the strength of the diabatic heating feedback in these two regions. Section 6 includes the conclusions and discussion.

\section{Data and methods}

This study mainly uses the ERA-Interim reanalysis dataset (Dee et al. 2011). The meteorological variables in the ERA reanalysis have a 6-h temporal resolution (at 0000, 0600, 1200, and 1800 UTC) and a spatial resolution of $0.7^{\circ}$. The precipitation variable used here is the short-range ECMWF forecast at a 12-h temporal resolution. The sum of the 0000-1200 and 1200-2400 UTC forecast accumulated precipitation is set as the daily mean precipitation. The date range for all the data is from 1979 to 2017.

The ECN region is defined as $112^{\circ}-122^{\circ} \mathrm{E}, 25^{\circ}-35^{\circ} \mathrm{N}$ and the SUS region is defined as $95^{\circ}-85^{\circ} \mathrm{W}, 28^{\circ}-38^{\circ} \mathrm{N}$. Thus, the EPEs in this study are regional-scale events, in contrast to convective-scale precipitation extremes (e.g., Hamada and Takayabu 2018). Our analyses focus on the summer season (June-August). An EPE is defined as a day with the daily maximum precipitation averaged over each regional box during each summer season. We exclude EPEs caused by tropical cyclones (two events in ECN and seven events in the SUS) since they have very different characteristics from those associated with extratropical perturbations. From 1979 to 2017, 39 EPEs in each region (see Table 1 for the dates of the events) are identified with a regional-boxaveraged mean precipitation of $17.5 \mathrm{~mm} \mathrm{day}^{-1}$ in ECN and $11.7 \mathrm{~mm} \mathrm{day}^{-1}$ in the SUS (Table 2). These events are used for composites to remove random noises in individual events and to obtain robust characteristics of EPEs.

The QG $\omega$ equation is a useful framework for understanding and quantifying the factors associated with 
TABLE 1. Dates of the extreme precipitation events.

\begin{tabular}{lllll}
\hline \hline & \multicolumn{3}{c}{ ECN } & \\
\hline 8 Jul 1979 & 23 Jun 1980 & 27 Jun 1981 & 1 Jun 1982 & 4 Jul 1983 \\
25 Jun 1985 & 15 Jun 1986 & 6 Jun 1987 & 21 Jun 1988 & 28 Aug 1989 \\
6 Jul 1991 & 5 Jul 1992 & 3 Jul 1993 & 16 Jun 1994 & 20 Jun 1995 \\
18 Aug 1997 & 24 Jun 1998 & 27 Jun 1999 & 2 Jun 2000 & 12 Jun 2001 \\
26 Jun 2003 & 13 Aug 2004 & 6 Aug 2005 & 13 Jun 2006 & 13 Jun 2007 \\
9 Aug 2009 & 19 Jun 2010 & 14 Jun 2011 & 13 Jul 2012 & 6 Jun 2013 \\
8 Aug 2015 & 3 Jul 2016 & 1 Jun 2017 & & 13 Jun 2008 \\
& & & & 4 Jul 2014 \\
11 Aug 1979 & 21 Jul 1980 & 5 Jun 1981 & 16 Jun 1982 & 26 Jun 1983 \\
16 Aug 1985 & 9 Jun 1986 & 1 Jul 1987 & 19 Jul 1988 & 8 Jun 1989 \\
31 Aug 1991 & 3 Jun 1992 & 6 Aug 1993 & 24 Jun 1994 & 4 Aug 1995 \\
17 Jun 1997 & 14 Jul 1998 & 26 Jun 1999 & 17 Jun 2000 & 12 Aug 2001 \\
6 Jun 2003 & 25 Jun 2004 & 1 Jun 2005 & 5 Jul 2006 & 6 Jul 2007 \\
30 Jul 2009 & 18 Aug 2010 & 15 Jul 2011 & 11 Jul 2012 & 4 Jul 2013 \\
27 Jun 2015 & 19 Aug 2016 & 5 Jun 2017 & & 12 Aug 2008 \\
\hline
\end{tabular}

vertical motion in EPEs (e.g., Martius et al. 2013; Nie et al. 2016). The QG $\omega$ equation may be written as (e.g., Holton 2004, 164-168)

$$
\begin{aligned}
\left(\partial_{p p}+\frac{\sigma}{f_{0}^{2}} \nabla^{2}\right) \omega= & -\frac{1}{f_{0}} \partial_{p} \operatorname{Adv}_{\zeta}-\frac{R}{p}\left(\frac{1}{f_{0}^{2}}\right) \nabla^{2} \operatorname{Adv}_{T} \\
& -\frac{R}{p}\left(\frac{1}{f_{0}^{2}}\right) \nabla^{2} Q
\end{aligned}
$$

where $\sigma=-(R T / p) \partial_{p} \ln \theta$ is the dry static stability, $\omega$ is the pressure vertical velocity, and $Q$ is diabatic heating. Also, $\zeta=\left(1 / f_{0}\right) \nabla^{2} \phi+f$ is the geostrophic absolute vorticity, $\phi$ is the geopotential, and $f_{0}$ is the reference value for the Coriolis parameter. The terms $\operatorname{Adv}_{\zeta}=$ $-\mathbf{V}_{g} \cdot \nabla \zeta, \operatorname{Adv}_{T}=-\mathbf{V}_{g} \cdot \nabla T$, and $\operatorname{Adv}_{q}=-\mathbf{V}_{g} \cdot \nabla q$ are the horizontal advection of (geostrophic) absolute vorticity $\zeta$, temperature $T$, and specific humidity $q$ by geostrophic winds, respectively. The QG $\omega$ equation states that to maintain the QG balance, vertical motion will be induced by ageostrophic adjustments whenever there is horizontal advection of absolute vorticity or temperature, or diabatic heating. There are several alternative ways to formulate the $\mathrm{QG}$ forcings in the $\mathrm{QG}$ $\omega$ equation, such as the $\mathbf{Q}$ vector formulation and the potential vorticity formulation (e.g., Horinouchi 2014; Davies 2015). The formulation as in Eq. (1) has the shortcomings that it is not Galilean-invariant and there is partial compensation between the vorticity and temperature advection terms. However, by separating the vorticity and temperature advection terms explicitly, it allows us to examine the relative importance of the two terms, which may be associated with two types of cyclogenesis: the vorticity advection dominant type and the thermal advection dominant type (e.g., Petterssen and Smebye 1971).
The total $\omega$ may be separated into a component explained by the QG $\omega$ equation $\left(\omega_{\mathrm{qg}}\right)$ and the remainder $\left[\omega_{\text {aqg }}\right.$, calculated as a residual term in Eq. (2)]. A significant advantage of the QG $\omega$ equation is its linearity, and thus, we may directly decompose $\omega_{\mathrm{qg}}$ into components forced by the large-scale advective forcings and diabatic heating. Therefore, we have

$$
\omega=\omega_{\mathrm{qg}}+\omega_{\mathrm{aqg}}=\omega_{\zeta}+\omega_{T}+\omega_{Q}+\omega_{\mathrm{aqg}} .
$$

The terms $\omega_{\zeta}, \omega_{T}$, and $\omega_{Q}$, are the vertical motion components corresponding to $\mathrm{Adv}_{\zeta}, \mathrm{Adv}_{T}$, and the $Q$ term, respectively, and their sum is $\omega_{\mathrm{qg}}$. These terms are calculated by solving the QG $\omega$ equation [Eq. (1)] on threedimensional sphere grids, including the right-hand-side (RHS) terms one by one (Stone 1968; Martius et al. 2013; Nie et al. 2016). In solving Eq. (1), the upper boundary condition is $\omega=0$ at a nominal tropopause of $100 \mathrm{hPa}$, and the lower boundary condition is setting $\omega$ to be its surface value at the surface level. The surfaces of the two regions are relatively flat, and the orography forced $\omega$ is very small; thus, it is not shown in the following analyses. Since the first two RHS terms of Eq. (1) represent the dynamic forcing of the adiabatic-balanced flow, the sum of $\omega_{\zeta}$ and $\omega_{T}$ may be called the dynamically forced vertical motion $\omega_{D}$, in contrast to the diabatic heating component of vertical motion $\omega_{Q}$. As shown later, for regional-scale EPEs, $\omega_{\mathrm{qg}}$ accounts for most of the total $\omega$ in the regions

TABLE 2. Precipitation $\left(\mathrm{mm} \mathrm{day}^{-1}\right)$ in reanalysis and approximated by $\omega$. The last column is for the diabatic heating feedback parameter $\alpha$.

\begin{tabular}{lcccccc}
\hline \hline & $P$ (reanalysis) & $P$ (scaling) & $P_{D}$ & $P_{Q}$ & $P_{\text {aqg }}$ & $\alpha$ \\
\hline ECN & 17.5 & 17.5 & 5.0 & 10.3 & 2.2 & 2.1 \\
SUS & 11.7 & 10.2 & 4.9 & 5.2 & 0.1 & 1.1 \\
\hline
\end{tabular}



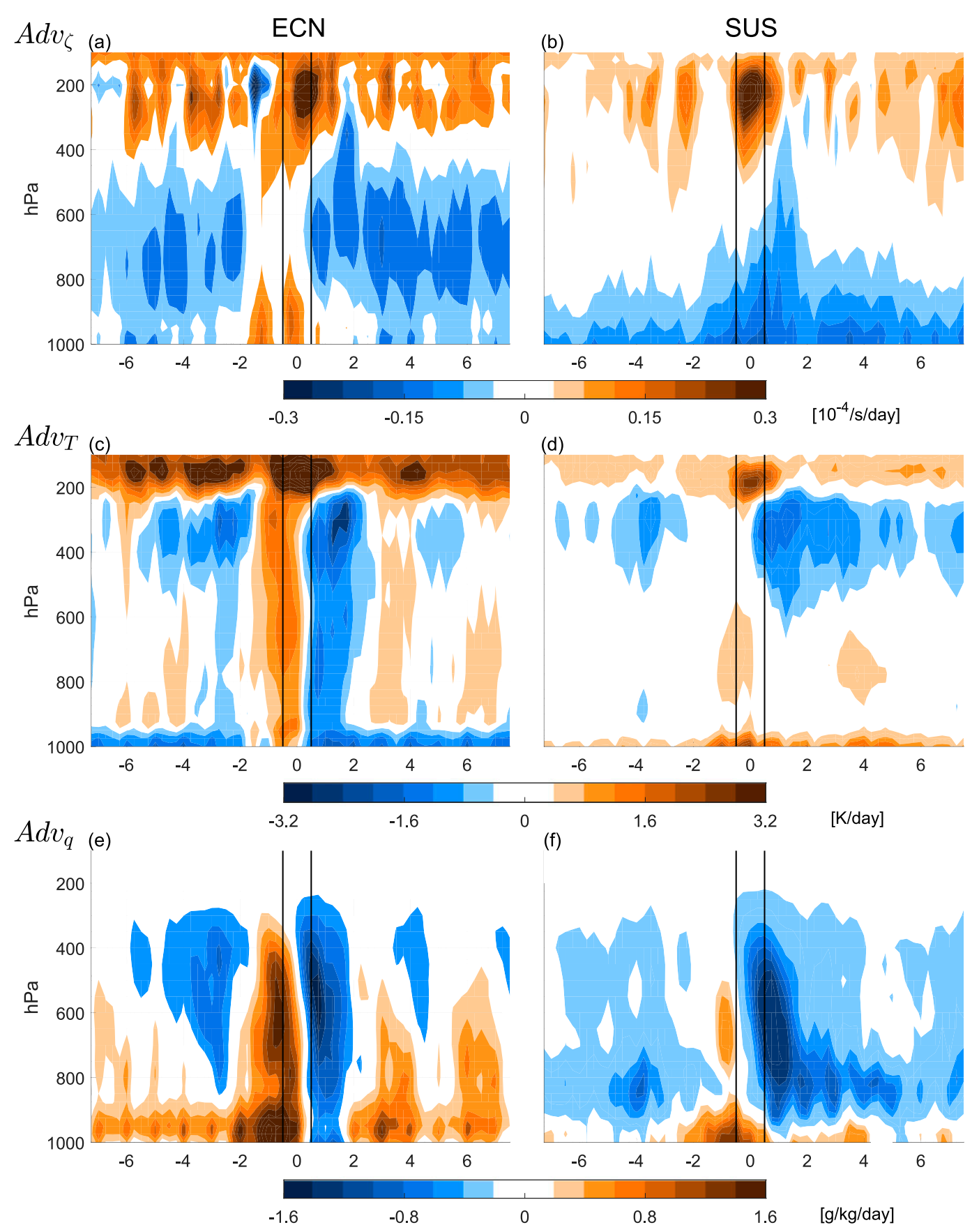

FIG. 1. The time evolution of the regional averaged advective forcings associated with the EPEs in (left) ECN and (right) the SUS. Shown are (a),(b) $\operatorname{Adv}_{\zeta}$, (c),(d) $\operatorname{Adv}_{T}$, and (e),(f) $\operatorname{Adv}_{q}$. The $x$ axis is time with day 0 marking the day with peak precipitation. The $y$ axis is the pressure level.

of events, which validates our uses of the QG $\omega$ in understanding EPEs.

\section{Dynamic forcings}

In this section, we examine the EPE-associated dynamic forcings. Figure 1 shows the time evolution of
$\mathrm{Adv}_{\zeta}, \mathrm{Adv}_{T}$, and $\mathrm{Adv}_{q}$ averaged over each regional box. Day 0 denotes the day with peak precipitation, while the negative (positive) sign denotes the days prior (after). Although $\operatorname{Adv}_{q}$ does not directly force vertical motion, it modifies the local convective conditions and thus affects the convective responses to the large-scale perturbations (Nie et al. 2016). First, let us focus on the 


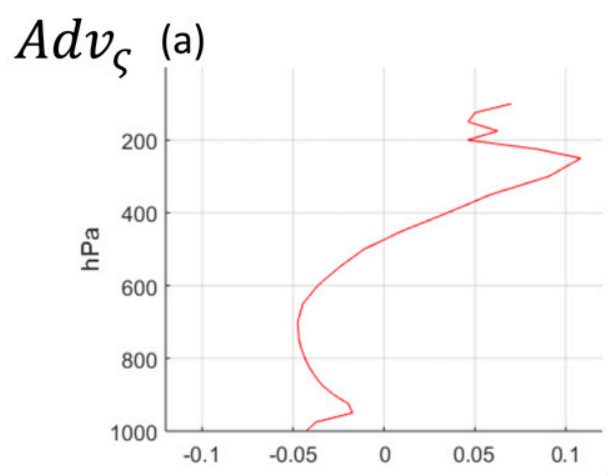

(b)

(c)
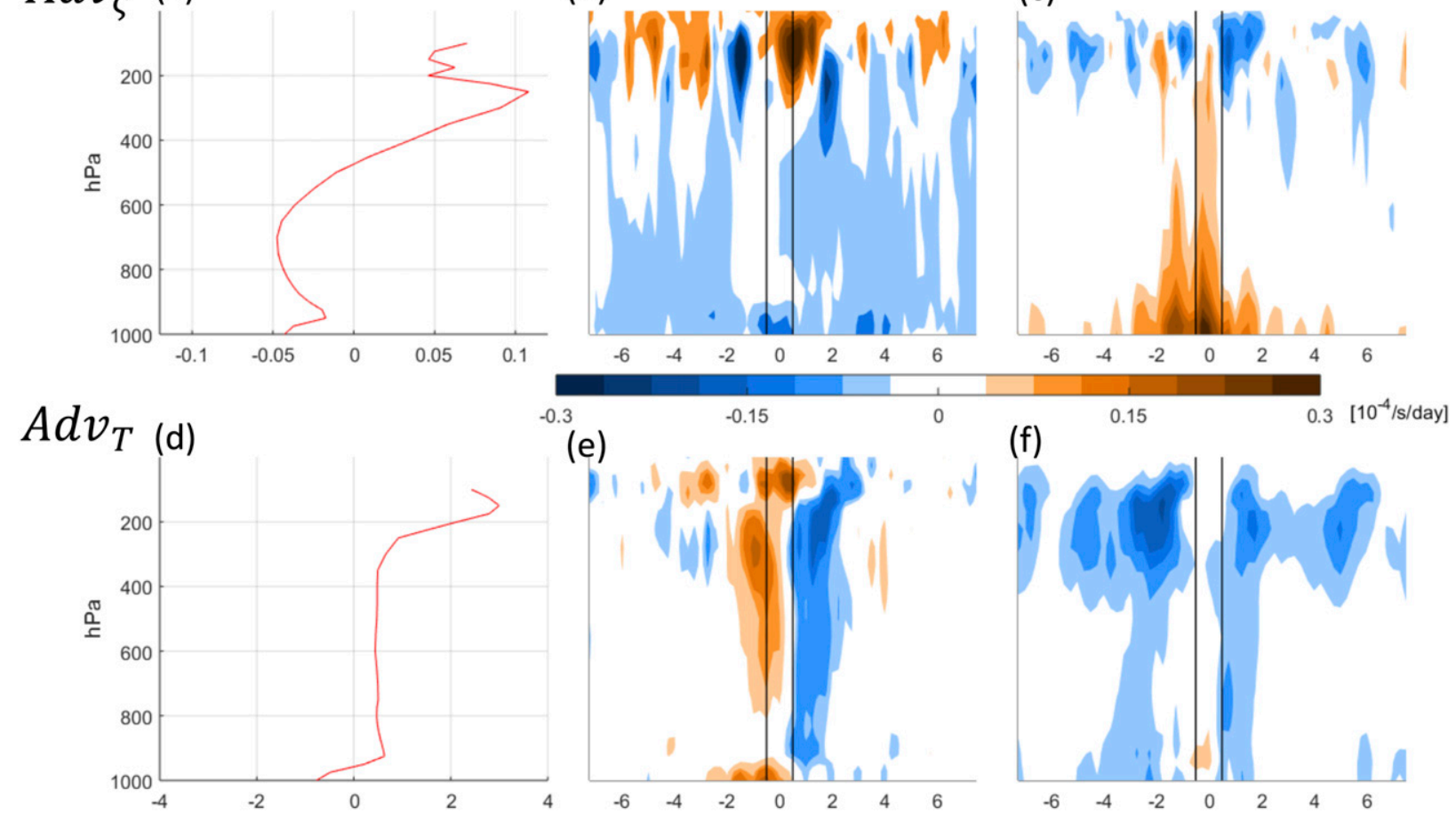

(e)

(f)
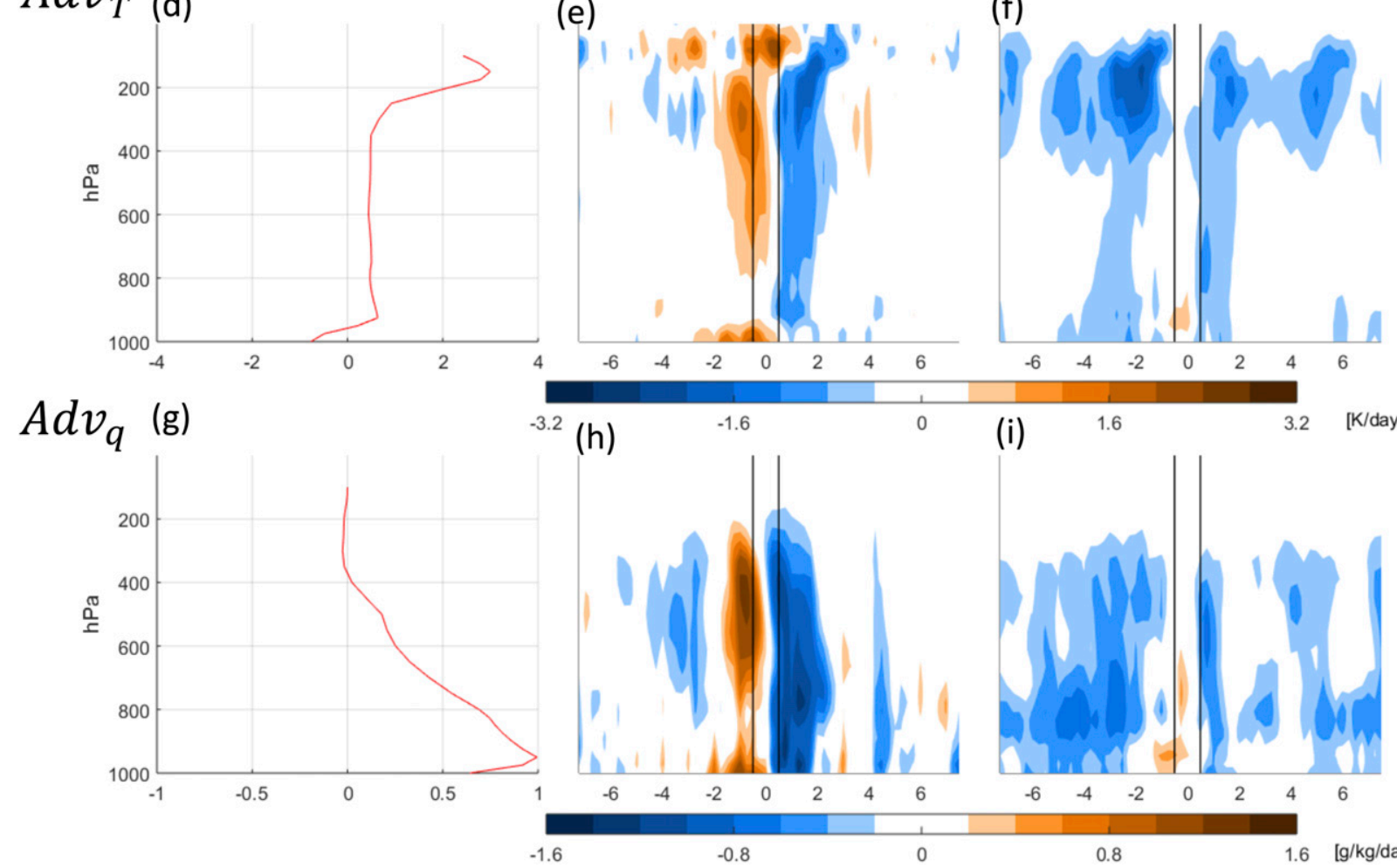

(i)

1.6

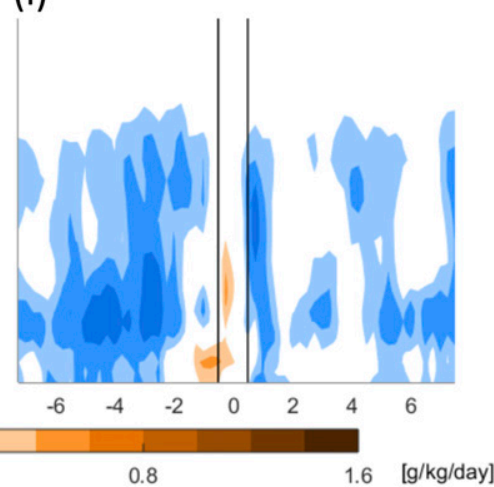

FIG. 2. The decomposition of advective terms for the ECN regions. Shown are (a)-(c) $\mathrm{Adv}_{\zeta},(\mathrm{d})-(\mathrm{f}) \mathrm{Adv}_{T}$, and (g)-(i) $\mathrm{Adv}_{q}$. (left) The RHS-1, (center) the sum of RHS-2 and RHS-3, and (right) the RHS-4 term of Eq. (3).

results for ECN. Over the 2 weeks around the EPEs, there is a background $\operatorname{Adv}_{\zeta}$ that is negative in the lower to middle troposphere $(900-400 \mathrm{hPa})$ and positive in the upper troposphere $(400-100 \mathrm{hPa})$ (Fig. 1a). The synoptic-scale $\mathrm{Adv}_{\zeta}$ is superimposed on the background. From day -2 to day 0 , the synoptic-scale $A_{d v_{\zeta}}$ is positive throughout the troposphere with a maximum value in the upper troposphere, followed by negative $\operatorname{Adv}_{\zeta}$ at day +1 . The background $\operatorname{Adv}_{T}$ is negative in the planetary boundary layer (PBL) and positive near the tropopause (Fig. 1c). There is also a warm background $\operatorname{Adv}_{T}$ extending throughout the troposphere (seen later in Fig. 2d). The synoptic scale $\operatorname{Adv}_{T}$ is positive throughout the troposphere preceding day 0 ; then, it becomes negative after day 0 . The background $\operatorname{Adv}_{q}$ is positive with a peak in the PBL and decreases upward since most atmospheric moisture is confined to the low levels. In the synoptic scale, there is a strong positive anomaly of $\operatorname{Adv}_{q}$ extending from the surface to $400 \mathrm{hPa}$ from day -2 to day 0 , which is followed again by negative anomalies. The negative $\operatorname{Adv}_{q}$ after day 0 (although the moisture flux convergence is still positive) is because the heavy rainfall makes the region as moist as or even moister than the equatorward regions upwind. 
In the SUS, the background $\mathrm{Adv}_{\zeta}$ in the upper troposphere is positive but relatively weak, and the negative values are close to the surface (Fig. 1b). In the synoptic scale, there is also a robust positive $\mathrm{Adv}_{\zeta}$ in the upper troposphere; however, $\mathrm{Adv}_{\zeta}$ is negative in the lower troposphere. The background $\operatorname{Adv}_{T}$ is both positive in the PBL and near the tropopause (Fig. 1d). For background moisture advection, there is a weak positive $\mathrm{Adv}_{q}$ in the PBL, while the levels above are negative with the peak occurring at about $850 \mathrm{hPa}$ (Fig. 1f). The synoptic-scale $\operatorname{Adv}_{T}$ and $\operatorname{Adv}_{q}$ in the SUS show similar signals to those in ECN, with a positive anomaly before day 0 and negative anomalies after day 0 , except these signals are much weaker.

The large-scale advective terms in Fig. 1 show mixed signals of the background circulations and synoptic perturbations. The background signals represent the contribution of the slow-varying general circulation, while the synoptic-scale signals represent the fast-varying perturbations that directly trigger EPEs. To separate these signals, we decompose each meteorological variable into an EPE-related background component (means from day -13 to day -4 and from day +4 to day +13 ) and an EPE-related synoptic-scale component (the differences between the total and the background component). For example, with temperature, we have $T=\bar{T}+T^{\prime}$, where $\bar{T}$ and $T^{\prime}$ denote the background and synoptic-scale component, respectively. Thus, the temperature advection may be decomposed into four parts:

$$
\begin{aligned}
\mathrm{Adv}_{T} & =-\mathbf{V}_{g} \cdot \nabla T \\
& =-\overline{\mathbf{V}_{g}} \cdot \nabla \bar{T}-\overline{\mathbf{V}}_{g} \cdot \nabla T^{\prime}-\mathbf{V}_{g}^{\prime} \cdot \nabla \bar{T}-\mathbf{V}_{g}^{\prime} \cdot \nabla T^{\prime}
\end{aligned}
$$

The RHS terms in Eq. (3) are the background advection (RHS-1; background temperature advection by background winds), the cross terms (RHS-2 and RHS-3), and the nonlinear advection (RHS-4; perturbation temperature advection by perturbation winds), respectively. Varying the criterion for the decomposition within several days leads to very similar results.

The decompositions of the advective terms based on Eq. (3) clearly separate the synoptic-scale advection [the cross terms and the nonlinear term in Eq. (3)] from its background, allowing us to identify their contributions and to compare their differences in the two regions separately. We first observe that every term in Eq. (3) has a nonnegligible contribution to the total advection. In the ECN, the background advective terms (Figs. 2a,d,g) show consistent but cleaner results compared with those described in Fig. 1. By examining the cross terms, we found that the RHS-2 term has similar patterns to the RHS-3 term but has the opposite sign and a larger amplitude (figures omitted). Thus, we only show the sum of the cross terms in Figs. 2 and
3 (middle columns). By comparing Fig. 2 with Fig. 1, we see that the cross terms contribute to most of the synoptic-scale signals in total advection, including the upper-level positive $\mathrm{Adv}_{\zeta}$ (Fig. 2b) and the positive then negative $\operatorname{Adv}_{T}$ (Fig. 2e) and $\operatorname{Adv}_{q}$ (Fig. 2h) around day 0. For EPEs, the nonlinear term contributes to the positive $\mathrm{Adv}_{\zeta}$ near the surface, which dominates the negative $\operatorname{Adv}_{\zeta}$ in the cross terms. Other than that result, the nonlinear term has a small contribution to the synoptic-scale signals. In contrast, the nonlinear term has sizeable projections on the background time scale (i.e., $-\overline{\mathbf{V}^{\prime} \cdot \nabla T^{\prime}}$ taking $T$ as example) due to the synoptic perturbations (which are not the ones associated with EPEs) in the ECN regions.

The decompositions of the advective terms in the SUS (Fig. 3) show generally weaker signals than those in ECN, with some differences. Again, the background advective terms confirm our previous observation. Compared to the results in ECN, there is no warm background advection in the free troposphere, except near the tropopause (Fig. 3d). The background moisture advection has positive peaks in a thin layer near the surface and is negative above (Fig. 3g). The cross terms also largely contribute to the synoptic-scale signals in total advection. Unlike in ECN, where the cross terms show signals with changed signs from day -2 to day 2 , in the SUS the cross terms show single peak signals around day 0 . The nonlinear advection in the SUS plays a larger role in EPEs than it does in ECN.

The advection of vorticity and temperature can dynamically force large-scale vertical motion that further causes heavy rainfall. The time evolution of the $\omega \mathrm{com}-$ ponents corresponding to the dynamic forcings are shown in Figs. 4a-d. The QG $\omega$ equation states that upward gradients of $\mathrm{Adv}_{\zeta}$ (e.g., positive on upper levels and negative on lower levels) and positive $\mathrm{Adv}_{T}$ induce ascent, while the downward gradients of $\mathrm{Adv}_{\zeta}$ and negative $\mathrm{Adv}_{T}$ induce descent. Consistent with these qualitative arguments, there is free tropospheric background ascent in $\omega_{\zeta}$ and $\omega_{T}$ in ECN (Figs. 4a,c) that corresponds to the background $\operatorname{Adv}_{\zeta}$ (Fig. 2a) and $\operatorname{Adv}_{T}$ (Fig. 2d). The importance of the background warm advection in the maintenance of the mei-yu front in East Asia has been pointed out in previous studies (Sampe and Xie 2010). Here, we show that the background $\operatorname{Adv}_{\zeta}$ is at least equally important. Before the ECN EPEs (day -2), there is actually weak descent in $\omega_{\zeta}$ (Fig. 4a), which corresponds to the upper-tropospheric negative $\mathrm{Adv}_{\zeta}$ in Fig. 1a. From day 0 to day +1 , the strong positive $\operatorname{Adv}_{\zeta}$ in the upper troposphere forces strong upward $\omega_{\zeta}$. The upward $\omega_{T}$ peaks at day -1 followed by descent at day +1 (Fig. 2c), which is consistent with the pair of positive and negative $\operatorname{Adv}_{T}$ values there. In the SUS, the background $\omega_{\zeta}$ is more bottom heavy than it is in ECN, which is consistent with 
$A d v_{\varsigma}(\mathrm{a})$

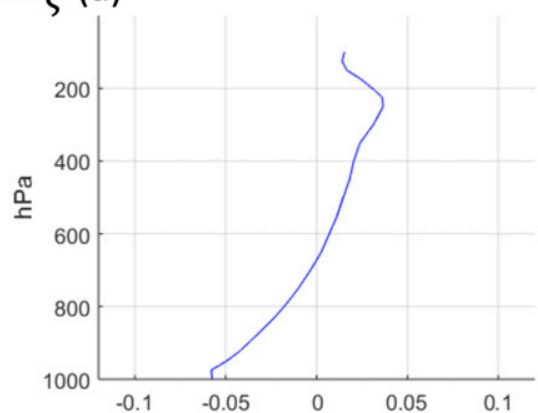

(b)

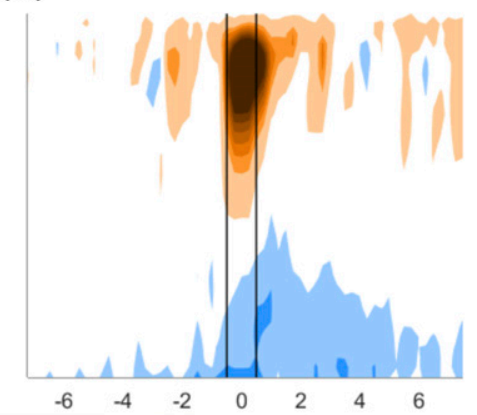

(c)

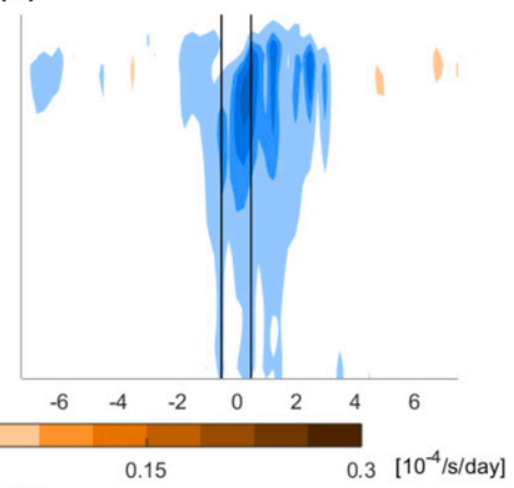

(f)

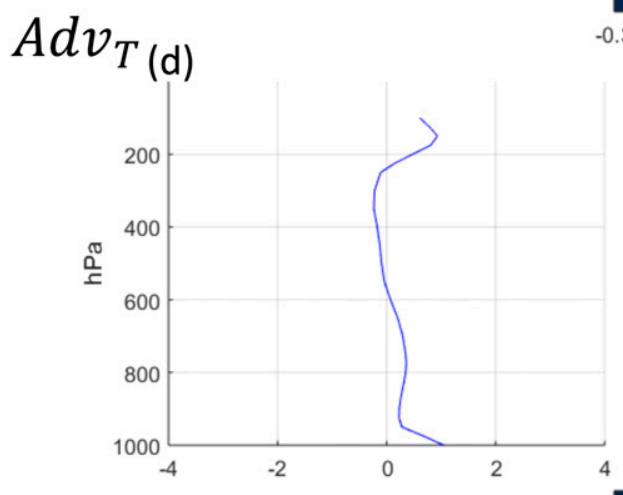

(e)
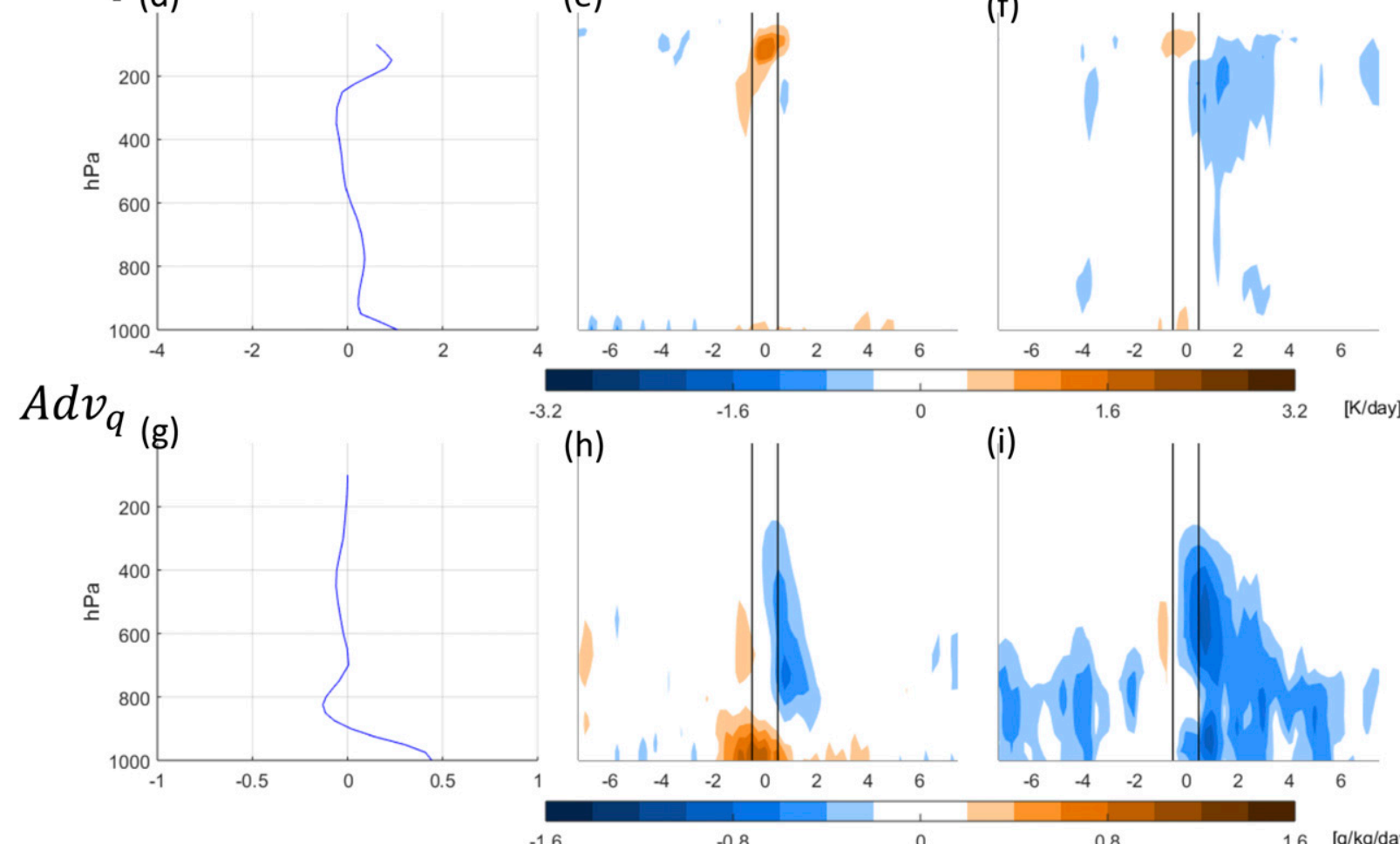

(h)

(i)
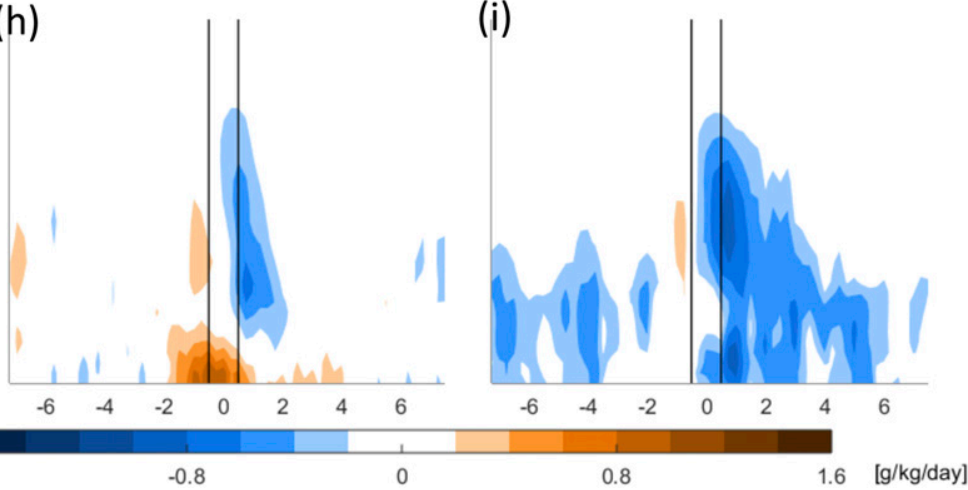

FIG. 3. As in Fig. 2, but for the SUS region.

the less tilted structure of $\operatorname{Adv}_{\zeta}$ (Fig. 3a). The background $\omega_{T}$ for the SUS is very weak. In the synoptic scale, $\omega_{\zeta}$ shows a single strong ascent over the EPE period. There is also an ascent in $\omega_{T}$ at day -1 ; however, the descent after day 0 is very weak. In the SUS, $\omega_{\zeta}$ is greater than $\omega_{T}$, which indicates that there is a relatively more important role for $\mathrm{Adv}_{\zeta}$ there; by contrast, in $\mathrm{ECN} \mathrm{Adv}_{\zeta}$ and $\mathrm{Adv}_{T}$ have similar importance in forcing EPEs.

\section{Horizontal patterns}

To better understand the large-scale advective terms seen in the previous section, we examine the horizontal patterns of the EPE-related background and synoptic components of meteorological variables as defined in the previous section. We first look at the EPE-related background geopotential $\bar{\phi}$ and horizontal winds $\overline{\mathbf{V}}$. At $850 \mathrm{hPa}$ (Fig. 5a), ECN is located at the west edge of the Pacific subtropical high. The southwesterlies bring air with low planetary vorticity, warm temperature, and moisture from the tropics (which is consistent with the sign of the advective terms in the low levels in the left column of Fig. 2). At $200 \mathrm{hPa}$ (Fig. 5e), the anticyclonic winds of the South Asia high (e.g., Rodwell and Hoskins 2001; Nie et al. 2010) bring northerlies over ECN, which is consistent with the upper-level positive $\operatorname{Adv}_{\zeta}$ in 


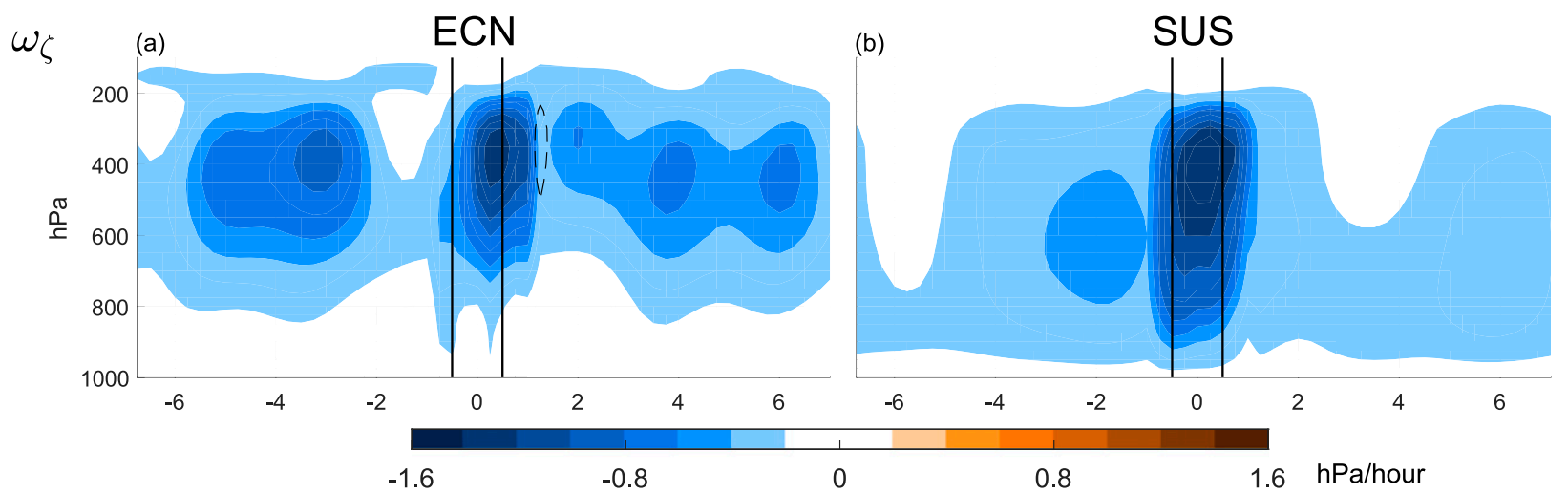

$\omega_{T}$

(c)

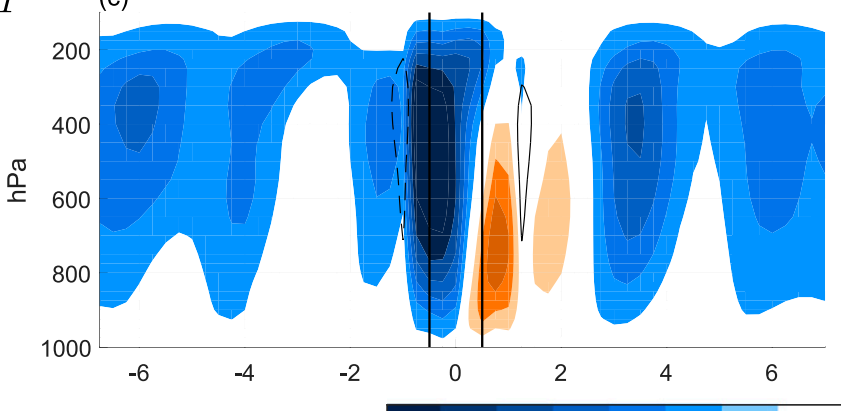

(d)
$\omega_{Q}$

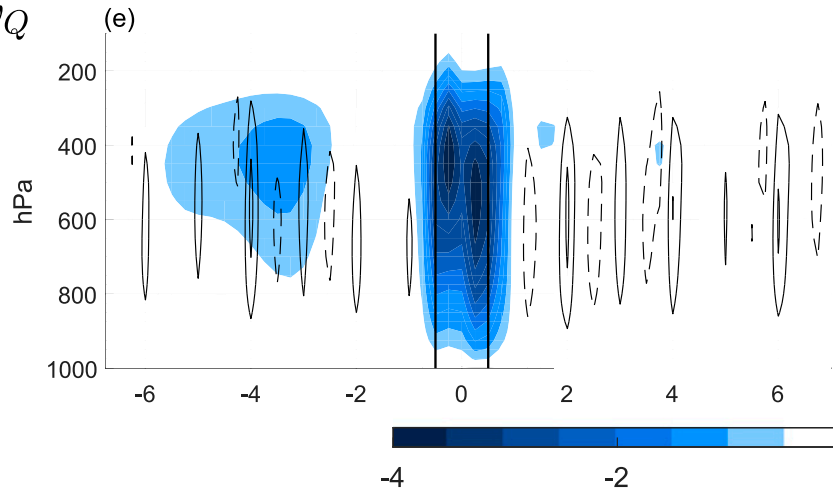

(f)

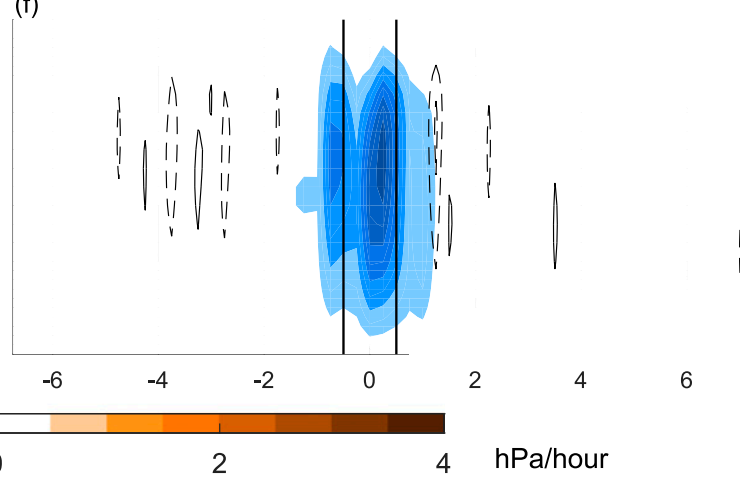

(h)

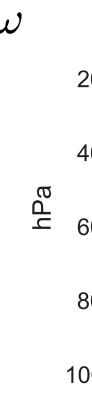
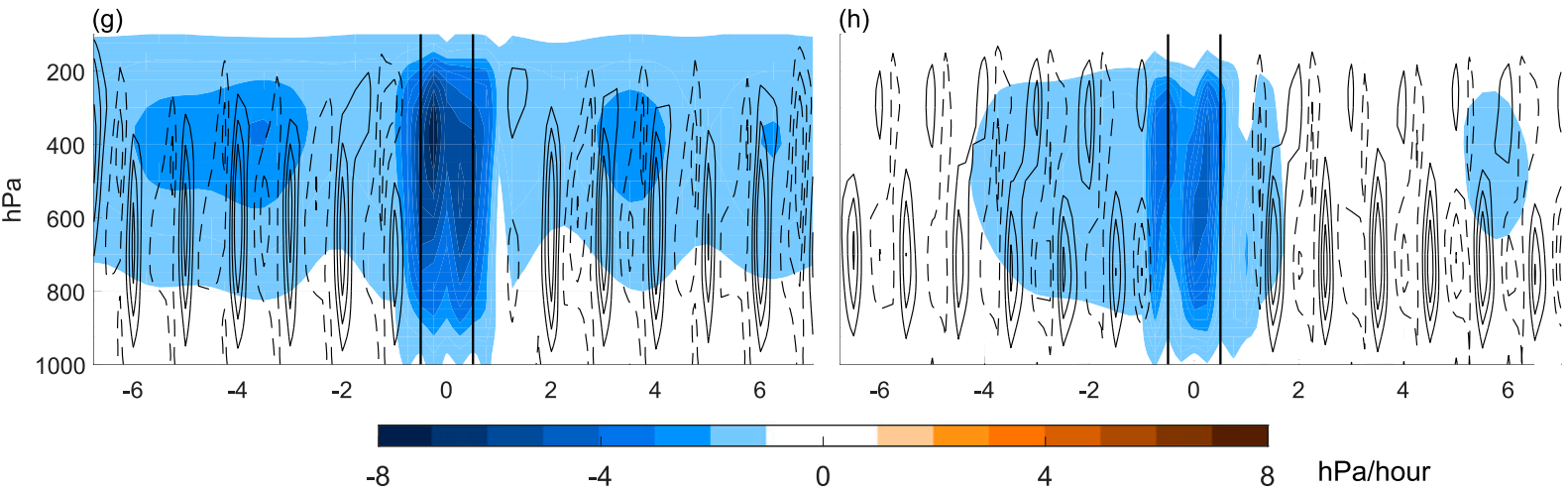

FIG. 4. The color maps denote the time evolution of $\omega$ components (with diurnal-cycle components subtracted). The black contours are the diurnal-cycle components (Fourier components with a time period equal to or shorter than 1 day). The black solid (dashed) lines denote positive (negative) contours with intervals of $0.4 \mathrm{hPa} \mathrm{h}^{-1}$. The zero contour lines are omitted. (left) ECN and (right) the SUS. Shown are (a),(b) $\omega_{\zeta}$, (c), (d) $\omega_{T}$, (e), (f) $\omega_{Q}$, and (g), (h) actual ERA-Interim-analyzed $\omega$. Note that the color bars of each row are different. The $x$ axis is time, with day 0 marking the day with peak precipitation. The $y$ axis is the pressure level. 

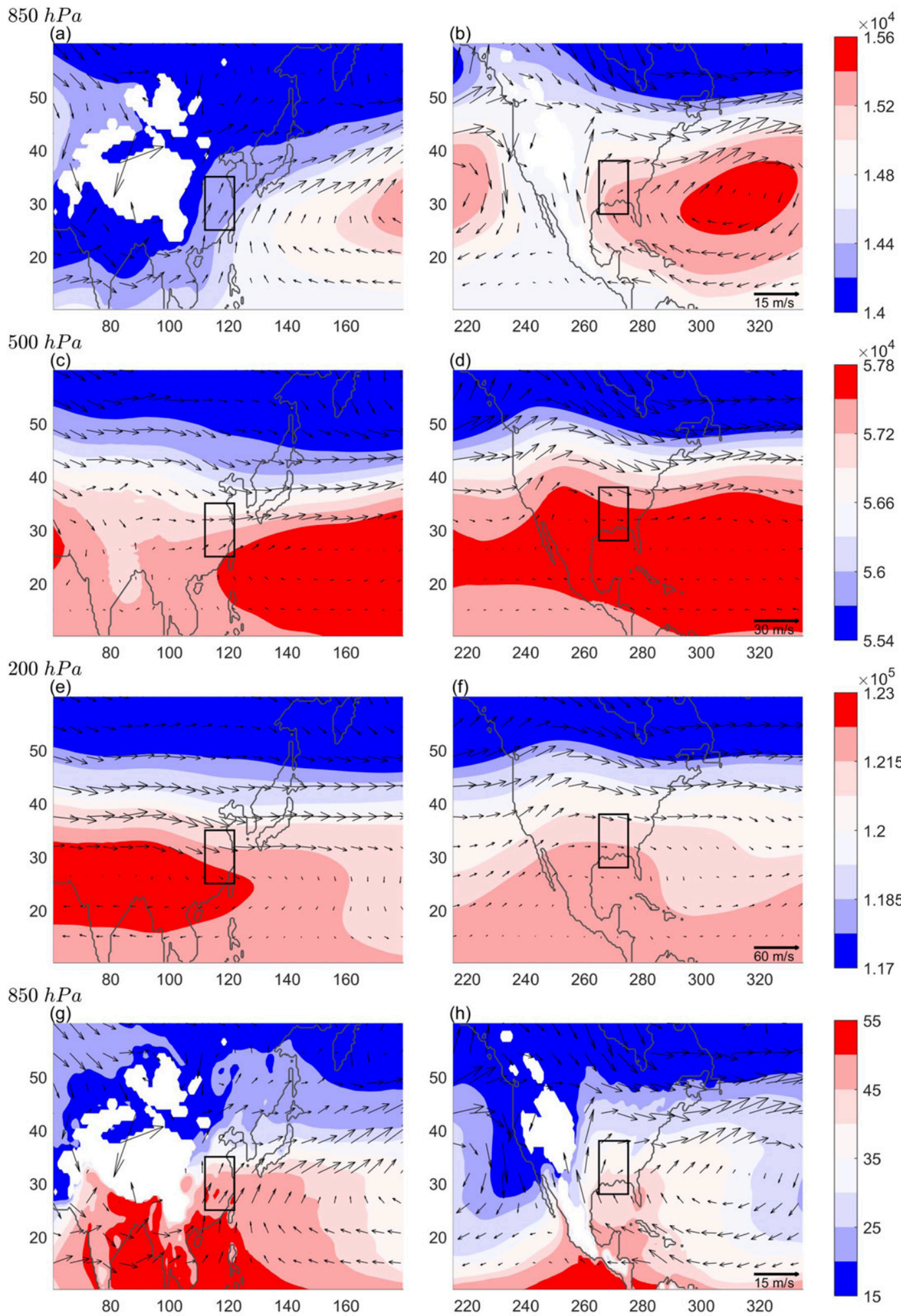

FIG. 5. The EPE-related background geopotential (color map; $\mathrm{m}^{2} \mathrm{~s}^{-2}$ ) and horizontal winds (vectors; $\mathrm{m} \mathrm{s}^{-1}$ ) at (a),(b) 850, (c),(d) 500, and (e),(f) $200 \mathrm{hPa}$. (g),(h) The background precipitable water (color map; mm) superimposed on 850 -hPa background winds. (left) The ECN region and (right) the SUS region. Grids with a surface pressure greater than the pressure levels are masked. 

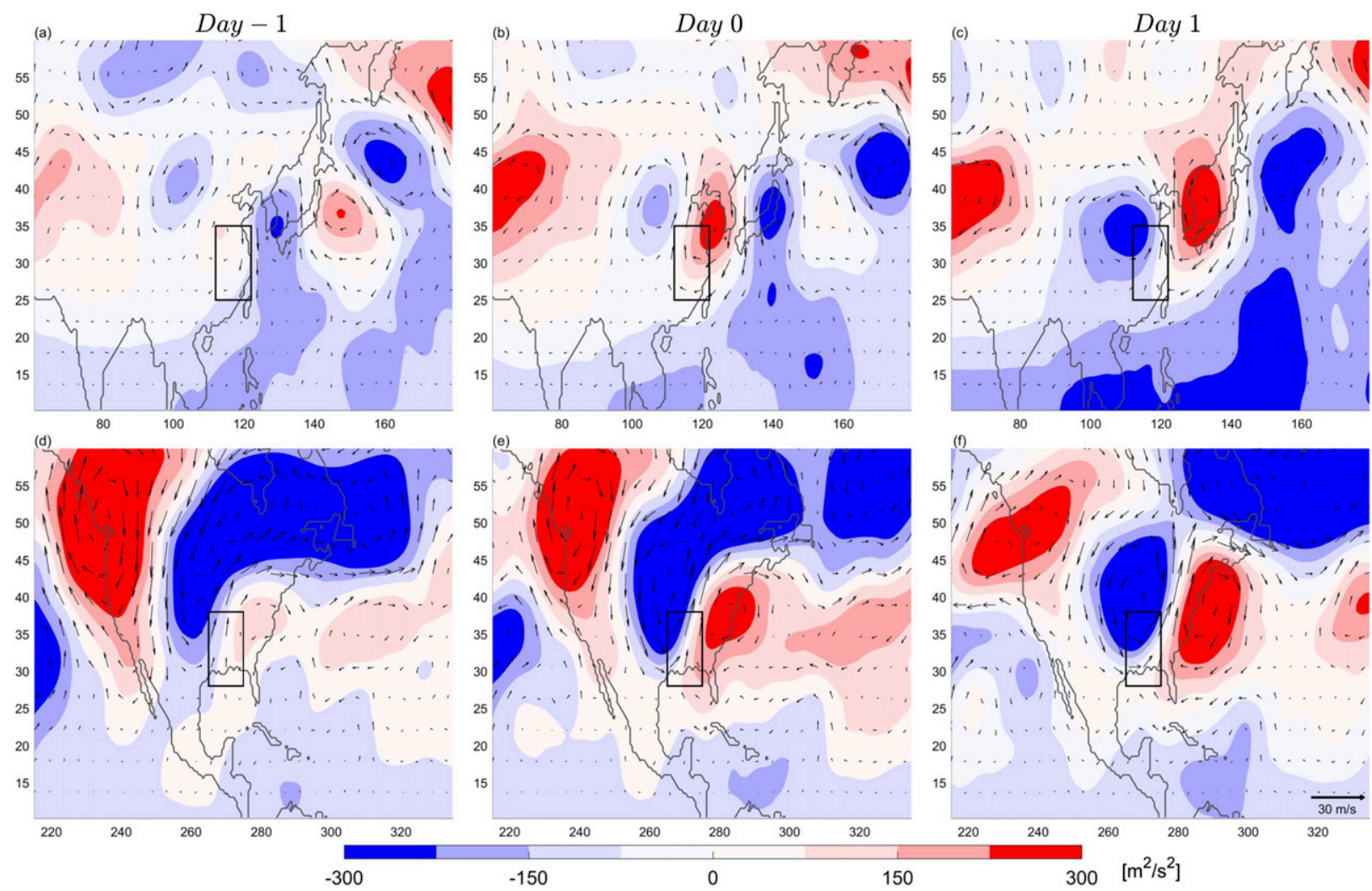

FIG. 6. The EPE-related synoptic-scale geopotential (color contours) and horizontal winds (vectors) at $200 \mathrm{hPa}$, for (a),(d) day -1, (b),(e) day 0 , and (c),(f) day +1 . (top) The ECN region and (bottom) the SUS region.

Fig. 2a. The northern part of the ECN regional box is covered by the midlatitude westerly jet, which brings warm air from the South Asia high to ECN. At $500 \mathrm{hPa}$ (Fig. 5c), the geopotential field is dominated by the Pacific subtropical high, and southwesterlies are formed over ECN due to the Pacific subtropical high and the westerly jet. Moving to the SUS region, at low levels, the Atlantic subtropical high induces southeasterlies (Fig. 5b), which leads to the negative $\mathrm{Adv}_{\zeta}$ shown in Fig. 3a. At $200 \mathrm{hPa}$ (Fig. 5f), there is a low-latitude high pressure system to the southwest of the SUS regional box. Together with the westerly jet, the northwesterlies provide strong upper-level positive $\operatorname{Adv}_{\zeta}$ and $\operatorname{Adv}_{T}$ (Figs. 3a,d). In the middle tropospheric (Fig. 5d), the geopotential field is influenced by both the low-latitude high pressure and the Atlantic subtropical high. A high pressure ridge over the Rocky Mountains, presumably caused by topographic effects, induces southward meridional winds in the SUS, in contrast to the northward meridional winds in ECN.

For the background moisture advection, one may examine the precipitable water superimposed on the $850-\mathrm{hPa}$ winds, since moisture concentrates at low levels. The low-level southwesterlies transport moisture from the west Pacific warm pool to ECN (Fig. 5g), consistent with the strong positive $\operatorname{Adv}_{q}$ in Fig. $2 \mathrm{~g}$. In contrast, the horizontal gradient of precipitable water in the SUS is weak (Fig. 5h). The Gulf of Mexico, despite its high sea surface temperature, is relatively dry due to the strong free tropospheric subsidence associated with the Atlantic subtropical high (Peixoto and Oort 1992, pp. 167 and 280). There, moisture is confined to the surface layer, and the humidity in the free troposphere is very low. As a result, in the SUS, $\mathrm{Adv}_{q}$ is only positive in the PBL and is negative above it (Fig. 3g). The total background moisture advection in the SUS is much weaker than that in ECN.

Next, we examine the EPE-related synoptic-scale components of the meteorological variables in Fig. 6. We only show results at $200 \mathrm{hPa}$ where the upstream influences of the synoptic-scale signals are most obvious. In the lower-to-middle troposphere, a cyclonic low pressure center, which is tilted westward with height, develops in both regions (figure omitted). In ECN, the EPEs are associated with a wave train that propagates over the northern part of the regional box (Figs. 6a-c). The wavelength of the wave train is relatively short $(\sim 3500 \mathrm{~km})$ and the propagation speed is fast; from 
day -1 to day +1 , the positive center has moved from the northwest corner of the regional box to about $15^{\circ} \mathrm{E}$. Associated with the wave train, the upper-level positive PV anomalies induce lower-level upwelling and southerlies for transporting moisture into the target region, creating a humid troposphere that is important for regional-scale heavy rainfall (Horinouchi 2014; Hamada and Takayabu 2018). The EPE-associated synopticscale perturbations in the SUS are quite different (Figs. 6d-f). A slow-moving, large-scale wave train (with a wavelength of $\sim 5000 \mathrm{~km}$ ) propagates from the North Pacific to the north of the SUS. The influence of the large-scale wave train on a heavy rainfall is a common feature in many regions; for example, the heavy rainfall in South Brazil is associated with the PacificSouth America pattern (Cavalcanti 2012; Mo and Higgins 1998). The strong low pressure center over northeast Canada develops a tail that extends to the west of the SUS. The secondary low pressure center slowly intrudes into the SUS and detaches from the parent wave train. At day +1 , a new positive geopotential center develops to the east of the SUS due to the diabatic heating of the heavy precipitation. This type of synoptic situation is usually called a $\mathrm{PV}$ intrusion (Massacand et al. 1998; Waugh and Polvani 2000; Funatsu and Waugh 2008). The differences in the synoptic-scale perturbations in ECN and the SUS are expressed in the advective terms in Figs. 2 and 3. The fast propagating wave train in ECN leads to changes in signs of the cross term in advection (Figs. 2b,e), whereas the PV intrusion in the SUS is a slow process, so the cross term in advection shows only a single peak in the signal (Figs. 3b,e).

\section{Diabatic heating feedback}

In previous sections, we examined the dynamic forcings associated with the adiabatic flow in EPEs and the horizontal patterns to understand the forcings. In this section, we focus on diabatic heating feedback on vertical motion. The questions to be addressed include determining how large the contribution of diabatic heating to $\omega$ is and what causes the differences in diabatic heating feedback in the two regions.

The time evolution of the diabatic heating component of $\omega\left(\omega_{Q}\right)$ and the total $\omega$ are shown in Figs. 4e-h. We first observe that there is an obvious diurnal cycle of $\omega$ corresponding to the diurnal cycle of convection. In both regions, $\omega_{Q}$ has the largest contribution to total $\omega$ among the four components in Eq. (2). In ECN, there are two peaks of $\omega_{Q}$ during the EPEs, which correspond to the peak of $\omega_{T}$ and peak of $\omega_{\zeta}$ (Figs. 4a,c), respectively. The first peak is more top-heavy than the second. In the SUS, there is only one peak of $\omega_{Q}$ at day 0 , which is mainly forced by $\omega_{\zeta}$ (Fig. 4b). Comparing $\omega_{Q}$ in both regions shows that $\omega_{Q}$ in $\mathrm{ECN}$ is much greater than that in the SUS.

Next, we examine the horizontal distributions of $\omega$ and its components at $500 \mathrm{hPa}$ (Fig. 7). As expected, regions with heavy rainfall (white contours in Fig. 7) collocate with centers of strong ascent. In ECN, one can see the background mei-yu front extending from Indochina to Japan (Fig. 7a). In ECN $\omega_{D}$ shows alternating ascent and descent centers extending from the upstream to the regional box, which is consistent with the synoptic perturbation of the upper tropospheric wave train (Fig. 7c; note that the domain in Fig. 7 is smaller than the domain of previous figures). Also, $\omega_{D}$ has a sizeable projection for the background mei-yu front, which confirms previous studies showing the important dynamic forcings on the mei-yu front (e.g., Sampe and Xie 2010; Gu et al. 2018). There is only one ascent center of $\omega_{D}$ over the SUS, corresponding to the PV intrusion process. In both regions $\omega_{Q}$ has a smaller spatial scale than $\omega_{D}$ and is concentrated in the regional boxes. It is interesting to note that in both regions, the centers of $\omega_{D}$ are several degrees north of the centers of $\omega_{Q}$, presumably because the environment is moister in the south and the moisture is transported from the south. This is consistent with the ideas of the ingredients-based forecasting of precipitation (e.g., Wetzel and Martin 2001) that dynamically forced ascent is only a necessary condition; heavy precipitation requires other important ingredients such as moisture and instability. We also observe that although $\omega_{D}$ has similar amplitude in these two regions, $\omega_{Q}$ in $\mathrm{ECN}$ is much greater than that in the SUS. The aQG component $\omega_{\text {aqg }}$ is small in the regional boxes, confirming our starting point that the QG $\omega$ is a good approximation of total $\omega$ in extratropical EPEs. The term $\omega_{\text {aqg }}$ is particularly large in the tropical rainbelt south of the regional boxes because when moving toward tropics, the Rossby radius of deformation approaches infinity, and perturbations of most length scale become the "small scale" perturbations that are not captured by QG theory.

The vertical profiles of $\omega$ and its components averaged over the two regions at day 0 are shown in Fig. 8. The term $\omega_{D}$ in the two regions has similar amplitudes, although $\omega_{D}$ in the SUS is more bottom heavy than that in ECN. It is the difference in $\omega_{Q}$ in the two regions that makes the total $\omega$ in ECN much greater than $\omega$ in the SUS, which is consistent with the intensity of EPEs in the two regions (Table 2). To better quantify the relative importance of $\omega$ components, one may convert $\omega$ to precipitation with a scaling proposed by O'Gorman and Schneider (2009) in which $P \approx-\left.(1 / g) \int \omega \partial_{p}^{*} q\right|_{\theta_{e}^{*}} d p$. This 
$\omega$

(a)

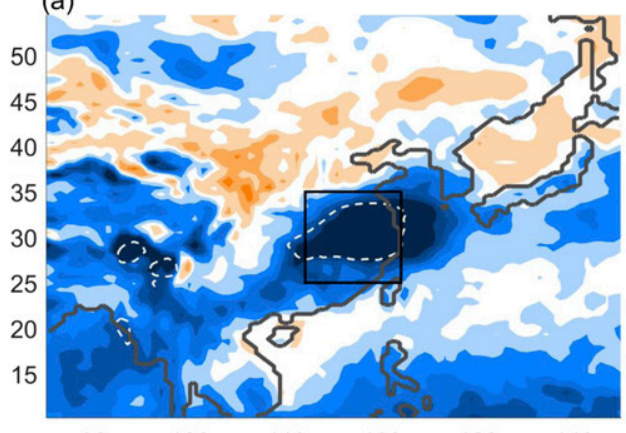

$\omega_{D}$

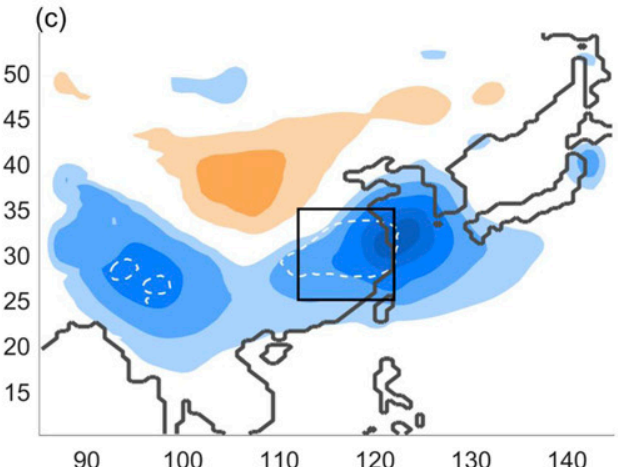

$\omega_{Q}$

(e)

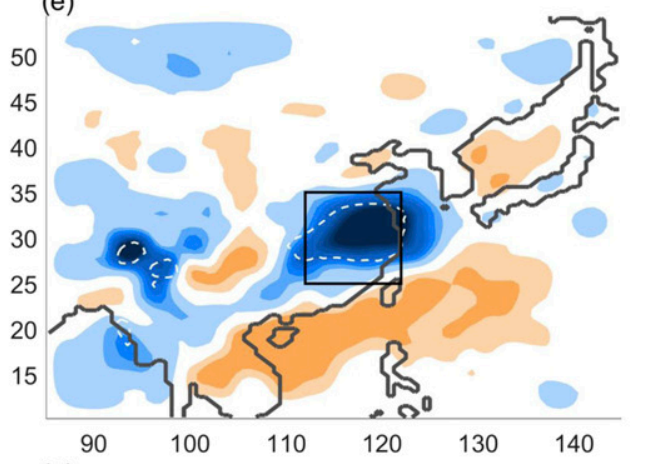

$\omega_{a q g(\mathrm{~g})}$

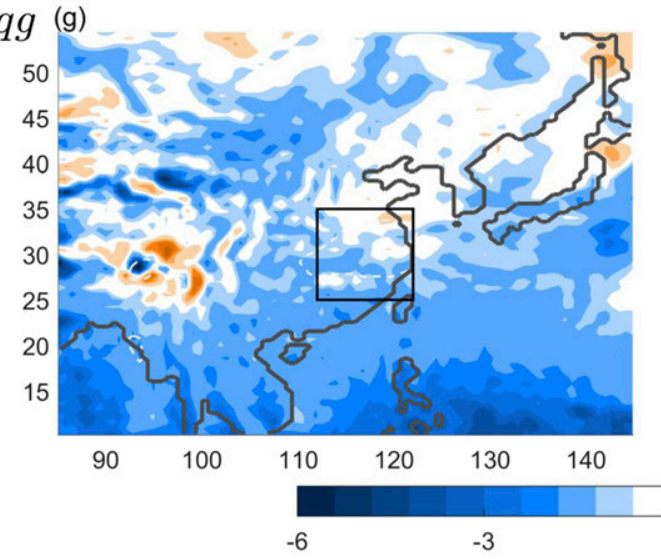

(b)

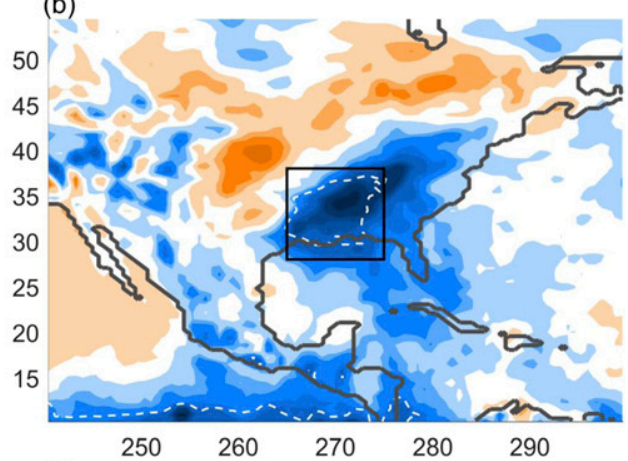

(d)

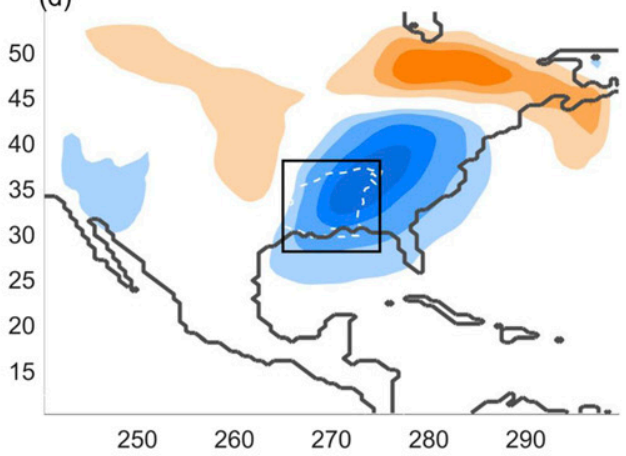

(f)

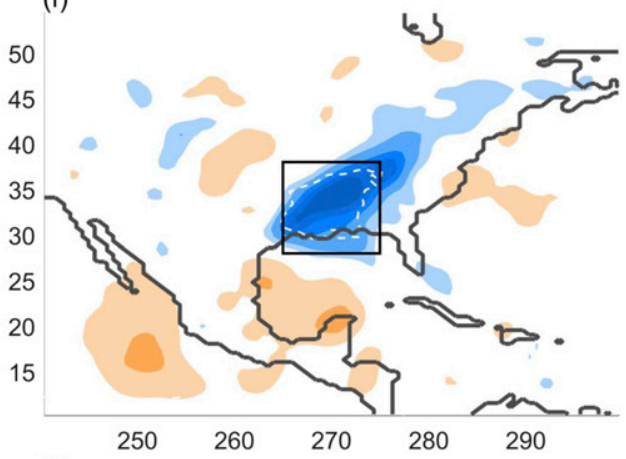

(h)

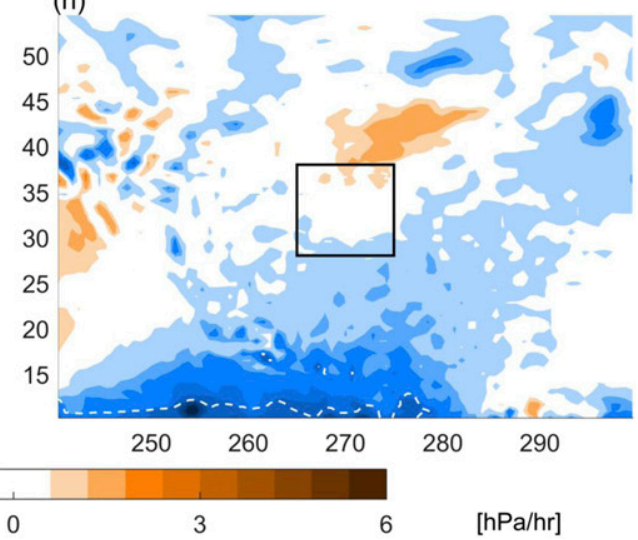

FIG. 7. The horizontal distribution of (a),(b) $\omega$, (c),(d) $\omega_{D}$, (e),(f) $\omega_{Q}$, and (g),(h) $\omega_{\text {aqg }}$ at $500 \mathrm{hPa}$ on day 0 . The white dashed contour lines denote a heavy-rainfall area (day 0 precipitation greater than $20 \mathrm{~mm} \mathrm{day}^{-1}$ in ECN and greater than $12 \mathrm{~mm} \mathrm{day}^{-1}$ in the SUS. 


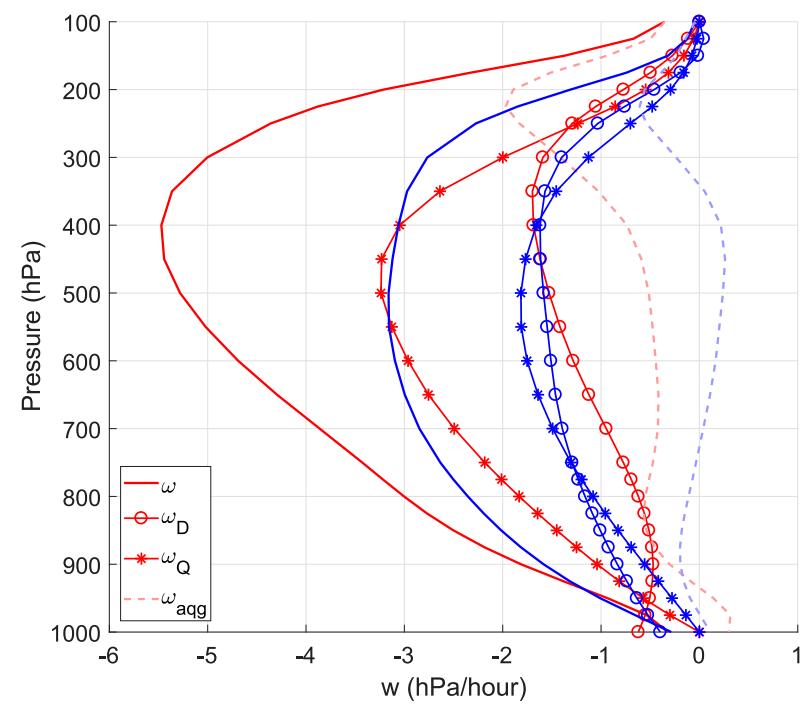

FIG. 8. The vertical profile of $\omega$ and its components averaged over the two regions on day 0 . The red lines are for the ECN region, and blue lines are for the SUS region.

scaling is the vertical integration of $\omega$ times the vertical gradient of saturation-specific humidity following a moist adiabatic process $\left.\partial_{p}^{*} q\right|_{\theta_{e}^{*}}$. Precipitation approximated by total $\omega$ with this scaling is very close to the same value in the reanalysis (Table 2). Similarly, we can calculate the approximate precipitation corresponding to each component of $\omega$ (Table 2). Precipitation corresponding to $\omega_{D}\left(P_{D}\right)$ in the two regions has a similar value; however, precipitation corresponding to $\omega_{Q}$ $\left(P_{Q}\right)$ in ECN is much greater than that in the SUS. One may define a diabatic heating feedback parameter $\alpha$ as the ratio between $P_{Q}$ and $P_{D}$ (Nie et al. 2018). The $\alpha$ parameter quantifies the diabatic heating feedback on precipitation due to QG adjustments, given a normalized unit of adiabatic large-scale perturbations. The $\alpha$ values in ECN and the SUS are 2.1 and 1.1 (the value of $\alpha$ in the SUS is similar to a case study of Texas extreme precipitation in 2015; Nie et al. 2018), respectively, indicating that there is much stronger diabatic heating feedback in ECN.

Here, we provide qualitative reasoning on the causes of the differences of $\alpha$ in the two regions. Because of the complexities in convection, quantitative analyses usually require help from numerical simulations. The diabatic heating feedback represents how local convection responds to large-scale perturbations in the coupled system, and thus it may mainly depend on the following factors (Nie and Sobel 2016): 1) the large-scale forcings (i.e., the combination of $\mathrm{Adv}_{\zeta}, \mathrm{Adv}_{T}$, and $\mathrm{Adv}_{q}$ ); 2) the local convective environments (i.e., the temperature and moisture profiles); and 3) the characteristic wavelength of the system, which determines how strongly convection and large-scale dynamics are coupled (Nie and Sobel 2016; Tandon et al. 2018a,b). Next, we examine these factors in the two regions to understand how they contribute to the differences of $\alpha$.

First, the large-scale forcings favor larger $\alpha$ in ECN due to the stronger $\operatorname{Adv}_{q}$ preceding the EPEs. Positive $\operatorname{Adv}_{q}$ moistens the local environments and strengthens the convective responses. The modification can be quite large (Nie et al. 2016) since convection sensitively depends on environmental moisture (e.g., Derbyshire et al. 2004). For dynamic forcings, $\omega_{D}$ in the SUS is more bottom heavy than in ECN. In addition, $\omega_{T}$ has more contributions to $\omega_{D}$ in ECN than in the SUS. Although warm advection forces ascent dynamically, it inhibits the development of convection by increasing atmospheric stability. These two factors favor larger $\alpha$ in the SUS; however, these effects are minor and should be dominated by the modification of $\operatorname{Adv}_{q}$.

Second, the local convective environments favor stronger diabatic heating feedback in ECN. The $T$ profile in $\mathrm{ECN}$ is approximately $1 \mathrm{~K}$ warmer than the profile in the SUS (Fig. 9a), and the dry static stabilities in the two regions are similar (Fig. 9c). The $q$ profile in ECN is significantly larger than the profile for the SUS (Fig. 9b), which is partly due to the warmer temperature and partly due to the higher relative humidity (Fig. 9d). The precipitable water at day 0 is $47.4 \mathrm{~mm} \mathrm{day}^{-1}$ in ECN and $40.9 \mathrm{~mm}$ day $^{-1}$ in the SUS. Numerical simulations showed that diabatic heating feedback is strongly proportional to the atmospheric moisture (Nie et al. 2016, 2018) because increased moisture leads to increased diabatic heating, which further drives a dynamic increase in large-scale ascent (and thus larger $\alpha$ ).

Finally, the characteristic wavelength of synoptic perturbations associated with EPEs in the ECN is only approximately half of the wavelength in the SUS (Fig. 6). The shorter the characteristic wavelength (i.e., the smaller the ratio between the characteristic wavelength and the Rossby radius of deformation), the more strongly the large-scale dynamics and the convection are coupled. A study using an idealized convection largescale coupled system supports the relationship between the wavelength and $\alpha$ (Nie and Sobel 2016). Thus, compared with the PV intrusion in the SUS, the shortwavelength wave train in ECN also leads to stronger diabatic heating feedback there.

\section{Conclusions and discussion}

Extratropical EPEs are usually associated with largescale disturbances, strong upward motions, and large latent heat release, all of which are closely coupled 

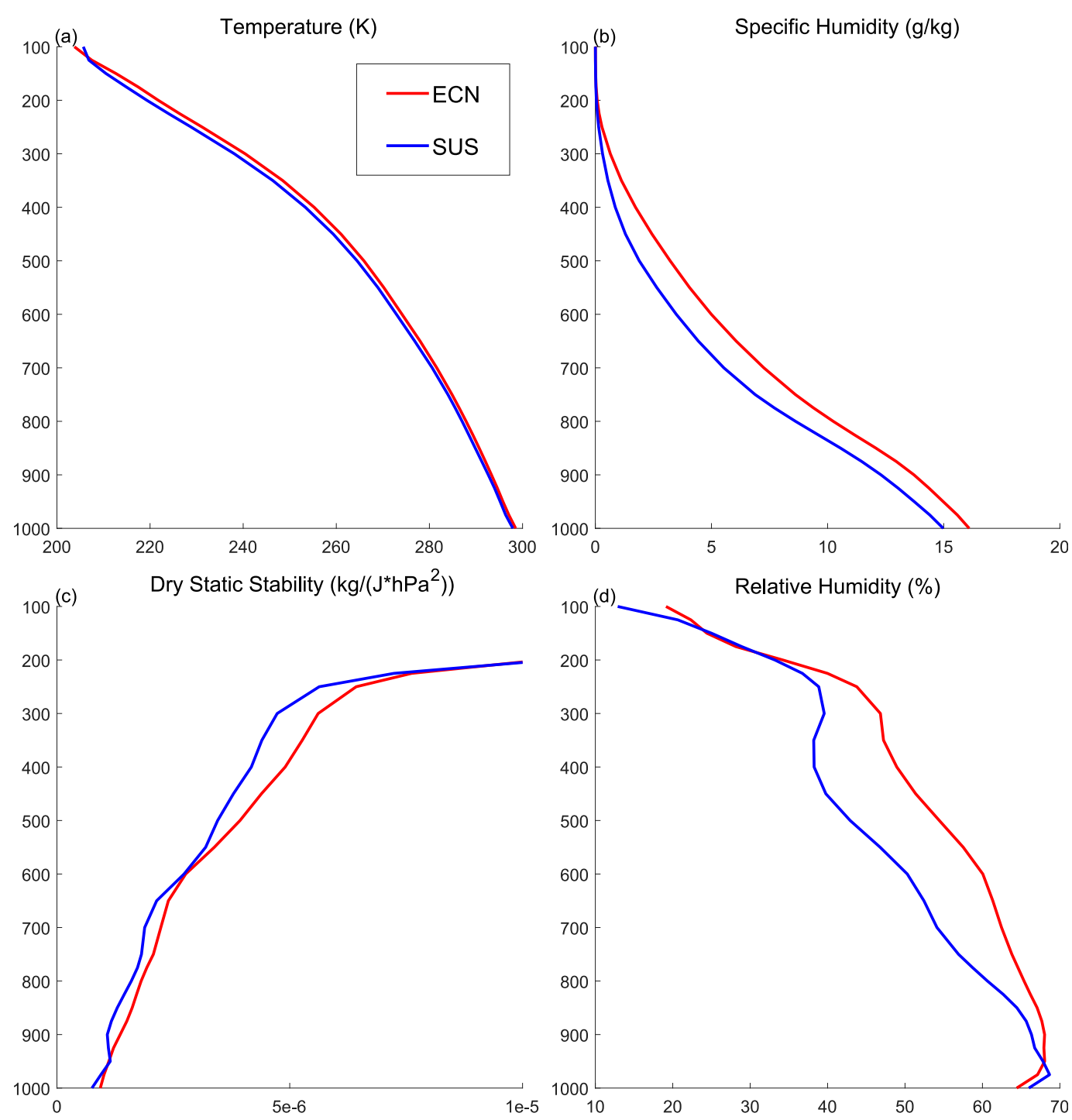

FIG. 9. The regional-box averaged (a) $T$, (b) $q$, (c) $\sigma$, and (d) relative humidity on day 0 .

together. Since the synoptic-scale perturbations are strongly constrained by the QG dynamics in the extratropics, we develop herein a deeper understanding of EPEs from the perspective of the QG $\omega$ equation. We examine the dynamic forcings and convective feedbacks associated with summer EPEs in two representative regions, East China and the southeastern United States, and compare their regional characteristics. The main findings are the following (see also the schematic in Fig. 10 with minor points):

1) EPEs in ECN and the SUS are associated with robust large-scale advective forcings, including positive temperature and moisture advection ahead of rainfall, and strong upper-level absolute vorticity advection during rainfall. The dynamic forcings $\left(\mathrm{Adv}_{\zeta}\right.$ and $\left.\mathrm{Adv}_{T}\right)$ induce a strong ascent that encourages local convection, while the moisture advection premoistens the local convective environment, leading to stronger convection later. The temperature and moisture advection in ECN are significantly stronger than those in the SUS.

2) There are regional differences in background circulations and synoptic perturbations associated with EPEs in ECN and the SUS. In ECN, the background absolute vorticity advection, warm advection, and moisture advection form the quasi-steady mei-yu front, which provides favorable conditions for synoptic perturbations to cause heavy rainfall. By contrast, in the SUS, there is only dynamically forced 

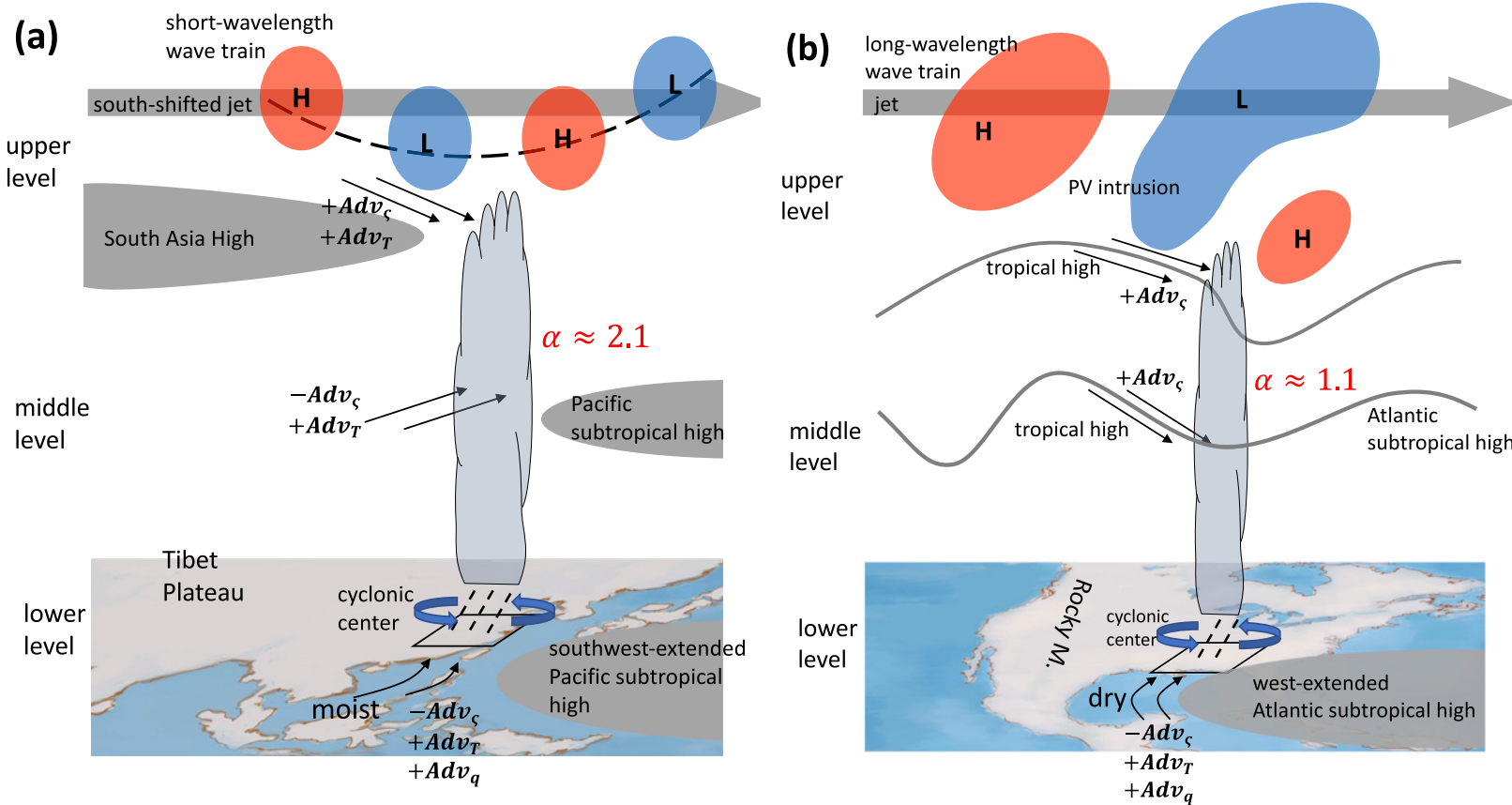

FIG. 10. Schematic of the factors associated with EPEs in (a) ECN and the (b) SUS. The factors in black indicate slow-varying backgrounds, and the factors in color (positive in red and negative in blue) indicate synoptic-scale perturbations. Arrows denote winds, and the associated advection that plays a role in EPEs is also marked. In ECN, the important background factors are the southwest-extended Pacific subtropical high (Zhou and Yu 2005), the South Asia high, and the south-shifted westerly jet (Chiang et al. 2017). In the synoptic scale, a short-wavelength wave train in the upper troposphere is associated with a westward-tilted low pressure center below in addition to strong and deep convection. In the SUS, the important background factors are the Atlantic subtropical high in the lower troposphere, the tropical high in the middle and upper troposphere, and the westerly jet. In the upper troposphere, a planetary-scale wave train provides strong PV intrusion from higher latitudes. The PV intrusion energizes the development of the cyclone and strong convection below. The size of the cloud symbol in ECN is larger than that in the SUS, which indicates that there is stronger diabatic heating feedback and precipitation there.

background ascent from absolute vorticity advection; the warm advection and moist advection are very weak. In the synoptic scale, the EPEs in ECN are associated with a short-wavelength wave train, while EPEs are triggered by large-scale PV intrusion in the SUS.

3) Although the dynamically forced vertical motions in the two regions have similar amplitudes, the diabatic heating feedback in ECN is much stronger than that in the SUS. Qualitative analyses suggest that this outcome may due to the stronger modification of moisture advection, convective environments with more humidity, and a stronger coupling between convection and large-scale dynamics due to the shorter wavelength of the synoptic disturbances in ECN compared to those in the SUS.

This paper is a diagnostic study with observational data. To quantitatively untangle the effects of background circulation and synoptic perturbations on the regional features of EPEs in ECN and the SUS, further studies are required with numerical simulations (e.g.,
Nie et al. 2016), such as a set of experiments with the same background large-scale or synoptic forcings. It is also worthwhile to examine the interannual variations among the extreme events. It has been known that interannual variability patterns, such as El Niño-Southern Oscillation, have significant influence on regional extreme precipitation (e.g., Dayan et al. 2015; Whan and Zwiers 2017). The analysis method used in this paper may fill the gap between remote teleconnections and local precipitation extremes. Over the long term, the responses of precipitation extremes to global warming will have dramatic regional variations (Alexander et al. 2006); the GCM results suggest that the increases in precipitation extremes in ECN will be greater than similar increases in the SUS (Kharin et al. 2007; Pfahl et al. 2017). One may use the QG $\omega$ equation to better understand the regional responses of extreme precipitation to climate change in extratropical regions.

Acknowledgments. The authors thank Takeshi Horinouchi and an anonymous reviewer for their helpful 
reviews. This research was supported by National Natural Science Foundation of China Grant 41875050. The dataset of the QG $\omega$ analyses in this study can be downloaded at https://www.jiniepku.com/download.html.

\section{REFERENCES}

Alexander, L. V., and Coauthors, 2006: Global observed changes in daily climate extremes of temperature and precipitation. J. Geophys. Res., 111, D05109, https://doi.org/10.1029/ 2005JD006290.

Cavalcanti, I. F. A., 2012: Large scale and synoptic features associated with extreme precipitation over South America: A review and case studies for the first decade of the $21 \mathrm{st}$ century. Atmos. Res., 118, 27-40, https://doi.org/10.1016/ j.atmosres.2012.06.012.

Chen, Y., and P. Zhai, 2014: Precursor circulation features for persistent extreme precipitation in central-eastern China. Wea. Forecasting, 29, 226-240, https://doi.org/10.1175/WAFD-13-00065.1.

Chiang, J. C. H., L. M. Swenson, and W. Kong, 2017: Role of seasonal transitions and the westerlies in the interannual variability of the East Asian summer monsoon precipitation. Geophys. Res. Lett., 44, 3788-3795, https://doi.org/10.1002/ 2017GL072739.

Clough, S. A., C. S. A. Davitt, and A. J. Thorpe, 1996: Attribution concepts applied to the omega equation. Quart. J. Roy. Meteor. Soc., 122, 1943-1962, https://doi.org/10.1002/qj. 49712253610

Davies, H. C., 2015: The quasigeostrophic omega equation: Reappraisal, refinements, and relevance. Mon. Wea. Rev., 143, 3-25, https://doi.org/10.1175/MWR-D-14-00098.1.

Dayan, U., K. Nissen, and U. Ulbrich, 2015: Review article: Atmospheric conditions inducing extreme precipitation over the eastern and western Mediterranean. Nat. Hazards Earth Syst. Sci., 15, 2525-2544, https://doi.org/10.5194/nhess-152525-2015.

Dee, D. P., and Coauthors, 2011: The ERA-Interim Reanalysis: Configuration and performance of the data assimilation system. Quart. J. Roy. Meteor. Soc., 137, 553-597, https://doi.org/ 10.1002/qj.828.

Derbyshire, S. H., I. Beau, P. Bechtold, J. Y. Grandpeix, J. M. Piriou, J. L. Redelsperger, and P. M. M. Soares, 2004: Sensitivity of moist convection to environmental humidity. Quart. J. Roy. Meteor. Soc., 130, 3055-3079, https://doi.org/10.1256/ qj.03.130.

Ding, Y., and J. C. Chan, 2005: The East Asian summer monsoon: An overview. Meteor. Atmos. Phys., 89, 117-142, https:// doi.org/10.1007/s00703-005-0125-z.

Funatsu, B. M., and D. W. Waugh, 2008: Connections between potential vorticity intrusions and convection in the eastern tropical Pacific. J. Atmos. Sci., 65, 987-1002, https://doi.org/ 10.1175/2007JAS2248.1.

Funk, T. W., 1991: Forecasting techniques utilized by the Forecast Branch of the National Meteorological Center during a major convective rainfall event. Wea. Forecasting, 6, 548-564, https://doi.org/10.1175/1520-0434(1991)006<0548: FTUBTF $>2.0 . \mathrm{CO} ; 2$

Gu, W., L. Wang, Z. Hu, K. Hu, and Y. Li, 2018: Interannual variations of the first rainy season precipitation over South China. J. Climate, 31, 623-640, https://doi.org/10.1175/JCLID-17-0284.1.
Hamada, A., and Y. N. Takayabu, 2018: Large-scale environmental conditions related to midsummer extreme rainfall events around Japan in the TRMM region. J. Climate, 31, 6933-6945, https://doi.org/10.1175/JCLI-D-17-0632.1.

Holton, J., 2004: An Introduction to Dynamic Meteorology. 4th ed. Elsevier Academic Press, 535 pp.

Horinouchi, T., 2014: Influence of upper tropospheric disturbances on the synoptic variability of precipitation and moisture transport over summertime East Asia and the northwestern Pacific. J. Meteor. Soc. Japan, 92, 519-541, https://doi.org/ 10.2151/jmsj.2014-602.

_ cipitation over summertime East Asia and the northwestern Pacific. J. Atmos. Sci., 74, 1233-1247, https://doi.org/10.1175/ JAS-D-16-0252.1.

Houze, R. A., Jr., K. L. Rasmussen, S. Medina, S. R. Brodzik, and U. Romatschke, 2011: Anomalous atmospheric events leading to the summer 2010 floods in Pakistan. Bull. Amer. Meteor Soc., 92, 291-298, https://doi.org/10.1175/2010BAMS3173.1.

Kharin, V. V., F. W. Zwiers, X. Zhang, and G. C. Hegerl, 2007: Changes in temperature and precipitation extremes in the IPCC ensemble of global coupled model simulations. J. Climate, 20, 1419-1444, https://doi.org/10.1175/JCLI4066.1.

Konrad, C. E., 1997: Synoptic-scale features associated with warm season heavy rainfall over the interior southeastern United States. Wea. Forecasting, 12, 557-571, https://doi.org/10.1175/ 1520-0434(1997)012<0557:SSFAWW >2.0.CO;2.

, and V. Meentemeyer, 1994: Lower tropospheric warm air advection patterns associated with heavy rainfall over the Appalachian region. Prof. Geogr., 46, 143-155, https://doi.org/ 10.1111/j.0033-0124.1994.00143.x.

Lareau, N. P., and J. D. Horel, 2012: The climatology of synopticscale ascent over western North America: A perspective on storm tracks. Mon. Wea. Rev., 140, 1761-1778, https://doi.org/ 10.1175/MWR-D-11-00203.1.

Lau, W. K., and K.-M. Kim, 2012: The 2010 Pakistan flood and Russian heat wave: Teleconnection of hydrometeorological extremes. J. Hydrometeor., 13, 392-403, https://doi.org/ 10.1175/JHM-D-11-016.1.

Luo, Y., H. Wang, R. Zhang, W. Qian, and Z. Luo, 2013: Comparison of rainfall characteristics and convective properties of monsoon precipitation systems over South China and the Yangtze and Huai River Basin. J. Climate, 26, 110-132, https:// doi.org/10.1175/JCLI-D-12-00100.1.

Maddox, R. A., C. F. Chappell, and L. R. Hoxit, 1979: Synoptic and meso- $\alpha$ scale aspects of flash flood events. Bull. Amer. Meteor Soc., 60, 115-123, https://doi.org/10.1175/1520-0477-60.2.115.

- F. Canova, and L. R. Hoxit, 1980: Meteorological characteristics of flash flood events over the western United States. Mon. Wea. Rev., 108, 1866-1877, https://doi.org/10.1175/15200493(1980)108<1866:MCOFFE > 2.0.CO;2.

Martius, O., C. Schwierz, and H. Davies, 2008: Far-upstream precursors of heavy precipitation events on the Alpine south-side. Quart. J. Roy. Meteor. Soc., 134, 417-428, https://doi.org/ 10.1002/qj.229.

— , and Coauthors, 2013: The role of upper-level dynamics and surface processes for the Pakistan flood of July 2010. Quart. J. Roy. Meteor. Soc., 139, 1780-1797, https://doi.org/10.1002/ qj.2082.

Massacand, A. C., H. Wernli, and H. C. Davies, 1998: Heavy precipitation on the Alpine southside: An upper-level precursor. Geophys. Res. Lett., 25, 1435-1438, https://doi.org/10.1029/ 98GL50869. 
Mo, K. C., and W. Higgins, 1998: The Pacific-South American modes and tropical convection during the Southern Hemisphere winter. Mon. Wea. Rev., 126, 1581-1596, https://doi.org/ 10.1175/1520-0493(1998)126<1581:TPSAMA > 2.0.CO;2.

Nie, J., and A. H. Sobel, 2016: Modeling the interaction between quasigeostrophic vertical motion and convection in a single column. J. Atmos. Sci., 73, 1101-1117, https://doi.org/10.1175/ JAS-D-15-0205.1.

_ - W. R. Boos, and Z. Kuang, 2010: Observational evaluation of a convective quasi-equilibrium view of monsoons. J. Climate, $\mathbf{2 3}$, 4416-4428, https://doi.org/10.1175/2010JCLI3505.1.

- D. Shaevitz, and A. H. Sobel, 2016: Forcings and feedback in the 2010 Pakistan flood: Modeling extreme precipitation with interactive large-scale ascent. J. Adv. Model. Earth Syst., 8, 1055-1072, https://doi.org/10.1002/2016MS000663.

— A. H. Sobel, D. Shaevitz, and S. Wang, 2018: Dynamic amplification of extreme precipitation sensitivity. Proc. Natl. Acad. Sci. USA, 115, 9467-9472, https://doi.org/10.1073/ pnas.1800357115.

O'Gorman, P. A., and T. Schneider, 2009: The physical basis for increases in precipitation extremes in simulations of 21 stcentury climate change. Proc. Natl. Acad. Sci. USA, 106, 14 773-14 777, https://doi.org/10.1073/pnas.0907610106.

Oh, H., K. J. Ha, and A. Timmermann, 2018: Disentangling impacts of dynamic and thermodynamic components on late summer rainfall anomalies in East Asia. J. Geophys. Res., 123, 8623-8633, https://doi.org/10.1029/2018JD028652.

Peixoto, J. P., and A. H. Oort, 1992: Physics of Climate. 1st ed. American Institute of Physics, $520 \mathrm{pp}$.

Petterssen, S., and S. J. Smebye, 1971: On the development of extratropical cyclones. Quart. J. Roy. Meteor. Soc., 97, 457-482, https://doi.org/10.1002/qj.49709741407.

Pfahl, S., P. A. O'Gorman, and E. M. Fischer, 2017: Understanding the regional pattern of projected future changes in extreme precipitation. Nat. Climate Change, 7, 423-428, https://doi.org/ 10.1038/nclimate3287.

Rodwell, M. J., and B. J. Hoskins, 2001: Subtropical anticyclones and summer monsoons. J. Climate, 14, 3192-3211, https://doi.org/ 10.1175/1520-0442(2001)014<3192:SAASM > 2.0.CO 2 .

Sampe, T., and S.-P. Xie, 2010: Large-scale dynamics of the meiyubaiu rainband: Environmental forcing by the westerly jet. J. Climate, 23, 113-134, https://doi.org/10.1175/2009JCLI3128.1.

Shaevitz, D. A., 2016: Extreme weather: Subtropical floods and tropical cyclones. Ph.D. dissertation, Columbia University, 109 pp.
Shiu, C.-J., S. C. Liu, C. Fu, A. Dai, and Y. Sun, 2012: How much do precipitation extremes change in a warming climate? Geophys. Res. Lett., 39, L17707, https://doi.org/10.1029/2012GL052762.

Stone, H. L., 1968: Iterative solution of implicit approximations of multidimensional partial differential equations. SIAM J. Numer. Anal., 5, 530-558, https://doi.org/10.1137/0705044.

Sun, J., and F. Zhang, 2017: Daily extreme precipitation and trends over China. Sci. China Earth Sci., 60, 2190-2203, https:// doi.org/10.1007/s11430-016-9117-8.

Tandon, N. F., J. Nie, and X. Zhang, 2018a: Strong influence of eddy length on boreal summertime extreme precipitation projections. Geophys. Res. Lett., 45, 10,665-10,672, https:// doi.org/10.1029/2018GL079327.

_, X. Zhang, and A. H. Sobel, 2018b: Understanding the dynamics of future changes in extreme precipitation intensity. Geophys. Res. Lett., 45, 2870-2878, https://doi.org/10.1002/ 2017GL076361.

van der Wiel, K., and Coauthors, 2016: The resolution dependence of contiguous U.S. precipitation extremes in response to $\mathrm{CO}_{2}$ forcing. J. Climate, 29, 7991-8012, https://doi.org/10.1175/ JCLI-D-16-0307.1.

Wang, W.-C., W. Gong, and H. Wei, 2000: A regional model simulation of the 1991 severe precipitation event over the Yangtze- Huai River valley. Part I: Precipitation and circulation statistics. J. Climate, 13, 74-92, https://doi.org/10.1175/ 1520-0442(2000)013<0074:ARMSOT>2.0.CO;2.

Waugh, D. W., and L. M. Polvani, 2000: Climatology of intrusions into the tropical upper troposphere. Geophys. Res. Lett., 27, 3857-3860, https://doi.org/10.1029/2000GL012250.

Wetzel, S. W., and J. E. Martin, 2001: An operational ingredientsbased methodology for forecasting midlatitude winter season precipitation. Wea. Forecasting, 16, 156-167, https://doi.org/ 10.1175/1520-0434(2001)016<0156:AOIBMF $>2.0 . C O ; 2$.

Whan, K., and F. Zwiers, 2017: The impact of ENSO and the NAO on extreme winter precipitation in North America in observations and regional climate models. Climate Dyn., 48, 14011411, https://doi.org/10.1007/s00382-016-3148-x.

Wirth, V., and J. Eichhorn, 2014: Long-lived Rossby wave trains as precursors to strong winter cyclones over Europe. Quart. J. Roy. Meteor. Soc., 140, 729-737, https://doi.org/10.1002/ qj. 2191.

Zhou, T.-J., and R.-C. Yu, 2005: Atmospheric water vapor transport associated with typical anomalous summer rainfall patterns in China. J. Geophys. Res., 110, D08104, https://doi.org/ 10.1029/2004JD005413. 